\title{
A combined GLAS and MODIS estimation of the global distribution of mean forest canopy height
}

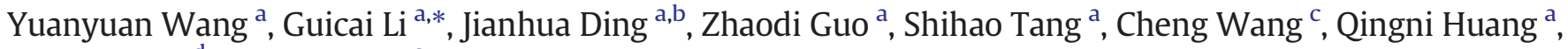 \\ Ronggao Liu ${ }^{\mathrm{d}}$, Jing M. Chen ${ }^{\mathrm{e}}$
}

a National Satellite Meteorological Center, China Meteorological Administration, Beijing, China

${ }^{\mathrm{b}}$ Center for Forest Operations and Environment, Northeast Forestry University, Harbin, China

c Institute of Remote Sensing and Digital Earth, Chinese Academy of Sciences, Beijing, China

d Institute of Geographical Sciences and Natural Resources Research, Chinese Academy of Sciences, Beijing, China

e International Institute for Earth System Science, Nanjing University, Nanjing, China

\section{A R T I C L E I N F O}

\section{Article history:}

Received 25 March 2014

Received in revised form 19 November 2015

Accepted 3 December 2015

Available online 17 December 2015

\section{Keywords:}

Mean forest canopy height

Geoscience Laser Altimeter System

Anisotropic factor

Balanced random forest

Wavelet method

\begin{abstract}
A B S T R A C T
Mapping the global distribution of forest canopy height is important for estimating forest biomass and terrestrial carbon flux. In this study, we present a global map of mean forest canopy height at $500 \mathrm{~m}$ spatial resolution obtained by combining Geoscience Laser Altimeter System (GLAS) data acquired from 2005 to 2006 and 13 ancillary variables, including seven climatic variables and six remote sensing variables (nadir BRDF-adjusted reflectance at red and NIR bands, tree cover, anisotropic factor, accumulated Enhanced Vegetation Index, and elevation). The original contributions of this study include the following: (1) The wavelet method was applied to complement the GLA14 product to identify the ground peak and the top-canopy peak. We found that it was useful for dealing with waveforms with low reconstruction accuracy. (2) GLAS data from the leafless season were not used for nonevergreen forest because the height retrieval results exhibited underestimation and strong variations. (3) The anisotropic factor (ANIF), an indicator related to surface structure, was included as an ancillary variable for the first time and was determined to be important for height modeling in the Asian and North American regions. (4) The balanced random forest (BRF) algorithm was applied to register GLAS mean forest canopy height to a $500 \mathrm{~m}$ grid considering the small proportion of extreme height classes (tall and short trees), and it achieved good performance in terms of modeling accuracy (RMSE $=2.75$ to $4.45 \mathrm{~m}$ ) and preserving data variation.

An inter-comparison among three global forest height maps [the present study, Lefsky (2010), and Simard et al. (2011)] was implemented in a pixel-by-pixel manner. High agreement $\left(R^{2}=0.73\right.$, RMSE $\left.=4.49 \mathrm{~m}\right)$ was determined between the present study and Simard et al., whereas the result from Lefsky was notably different from the other two results $\left(R^{2}=0.14\right.$, RMSE $=8.92 \mathrm{~m}$, compared with the present study; $R^{2}=0.11$, RMSE $=$ $11.19 \mathrm{~m}$, compared with Simard et al.). Large disparities were generally associated with evergreen broadleaf forests in South America, deciduous needleleaf forests in Europe and Russian North Asia, and evergreen needleleaf forests on the West Coast of North America. Differences in the height metric were a main factor affecting the disparities among the three results. Validation against field survey data acquired from the Distributed Active Archive Center indicated the accuracy of our mean forest canopy height map $\left(\mathrm{R}^{2}=0.63\right.$, $\left.\mathrm{RMSE}=4.68 \mathrm{~m}, \mathrm{n}=59\right)$.
\end{abstract}

(C) 2015 Elsevier Inc. All rights reserved.

\section{Introduction}

\subsection{Background}

Forests are a significant terrestrial carbon sink (Houghton, 2005), and quantitative information on the global distribution of forest canopy height is valuable for calculations of forest biomass and estimations of terrestrial carbon flux. Although forest inventory data provide valuable information on forest biomass and height, their application for global-scale studies is

\footnotetext{
* Corresponding author.

E-mail addresses: ligc@cma.gov.cn, guicai_li@163.com (G. Li).
}

limited by methodological differences and an absence of observations in remote areas (Pflugmacher, 2007). Remote sensing is an efficient means of repeatedly monitoring the Earth in a consistent manner. However, forest biomass and height mapping using existing optical and thermal sensors is challenging because these sensors are primarily responsive to canopy cover, rather than vertical structure (Chopping et al., 2008). High resolution stereo-optical and radar images have been used to map forest structure, but these are of limited use in dense or structurally heterogeneous forests (Hyde et al., 2006; Boudreau et al., 2008).

A promising remote sensing instrument for forest height and biomass mapping is light detection and ranging (Lidar), which can provide direct measurements of forest vertical structure by measuring the time 
elapsed between an emission of a laser pulse and a return signal from a target (Harding \& Carabajal, 2005; Lee et al., 2011). Airborne Lidar has been used successfully for forest biomass and height mapping across various landscapes (Anderson et al., 2006; Boudreau et al., 2008); however, this instrument is not widely available and regular updates are not feasible (Selkowitz et al., 2012). The Geoscience Laser Altimeter System (GLAS), the first spaceborne Lidar system, was launched in 2003. GLAS offers an unprecedented opportunity for estimating forest canopy height and biomass at regional to global scales in a spatially consistent manner (Rosette et al., 2008).

Despite the great potential provided by GLAS data, obtaining a spatially continuous forest height map with high accuracy is far from straightforward for several reasons. First, the waveform recorded by the GLAS sensor is affected by not only the vegetation canopy but also by thin clouds, atmosphere, topography, soil moisture, and other factors (Iqbal, 2010; Rosette et al., 2010). Among these factors, the slope effect is the most significant. The waveform shape can be regarded as a product of the complex interaction between surface and forest structure within the area illuminated by the laser (Lefsky et al., 2007). Therefore, forest canopy height retrieval can be very problematic over mountainous regions (Harding \& Carabajal, 2005; Chen, 2010; Duncanson et al., 2010). For example, many studies have shown that forest canopy height is very difficult to determine when the surface slope is greater than $15^{\circ}$. Additionally, if the forest structure is highly complex, slopes greater than $10^{\circ}$ can be problematic (Hilbert and Schmullius, 2012). Slope correction will continue to be an open issue for large-footprint Lidar data processing (Lefsky et al., 2007; Simard et al., 2011). Second, GLAS shots, with an average diameter of $65 \mathrm{~m}$, are acquired along transects at intervals of $170 \mathrm{~m}$ over several tens of kilometers, so producing spatially contiguous forest height requires the integration of ancillary data that are spatially contiguous and related to some extent to forest canopy height (Li et al., 2011; Selkowitz et al., 2012). Careful selection of these ancillary data and a modeling algorithm is important for the successful mapping of forest canopy height. For example, Selkowitz et al. (2012) found that snow-covered MISR data are more effective than MODIS data for mapping canopy height in boreal forest regions because snow background contrasts significantly with the canopy and does not change dramatically across space.

\subsection{Previous studies on global mapping of forest height}

The requirement for a map of global forest canopy height for biomass estimation has become increasing apparent as global carbon cycle research has intensified (Zolkos et al., 2013). Lefsky (2010) produced the first global forest canopy height map, which includes 4.4 million forest patches, by combining GLAS and $500 \mathrm{~m}$ MODIS data. This researcher built empirical regression models to estimate Lorey's height from waveform parameters (indices of total waveform extent and the height of the 10th and 90th percentiles of waveform energy), which were confirmed to be capable of correcting the slope effect in his research (Lefsky et al., 2007). The height estimates at the footprint level were then used for biomass mapping in tropical regions across three continents (Saatchi et al., 2011). Simard et al. (2011) produced the second global forest canopy height map by combining GLAS data and seven ancillary variables, including climatic and remote sensing data. These researchers argued that the patch results of Lefsky can be difficult to interpret at coarse resolution and that slope correction through empirical regression is site specific and so may introduce significant biases. Therefore, they produced a forest height map at a spatial resolution of $1 \mathrm{~km}$. To minimize the influence of slope, they only preserved waveforms located in slopes of less than $5^{\circ}$ and for which the bias correction, calculated by multiplication of footprint diameter and tangent of slope, Df $x$ $\tan$ (slope), was less than $25 \%$ of the measured RH100. Their result had an RMSE of $6.1 \mathrm{~m}$ when compared with 66 FLUXNET data. Los et al. (2011) produced a coarse resolution $\left(0.5^{\circ} \times 0.5^{\circ}\right)$ vegetation height product between $60^{\circ} \mathrm{S}$ and $60^{\circ} \mathrm{N}$ for use in climate and ecology models. In their study, all GLAS data collected from 2003 to 2009 were used, and several filters were designed to identify and eliminate the GLAS data that could be affected by cloud, atmosphere, terrain, and other factors. The authors argued that their estimates had more realistic characteristics, such as dominant vegetation height for tropical forests of 30 to $60 \mathrm{~m}$ in contrast to estimates from Lefsky's work of 20 to $40 \mathrm{~m}$.

\subsection{Objectives of this study}

Despite the previously mentioned commendable works on mapping global forest canopy height, many issues require further investigation. First, most of the existing algorithms depend on six Gaussian fits to the waveform data provided in the GLA14 product (Rosette, 2008; Los et al., 2011; Simard et al., 2011). Although GLA14 performs waveform decomposition effectively, it only provides up to six modes, which may be insufficient to fit the waveform well under certain conditions (Duong et al., 2009; Iqbal, 2010). It has been found that Gaussian fitting does not capture the last mode and thus misses the ground peak return, which is vital for tree height estimation (Iqbal, 2010). Wang et al. (2013) recently proposed a wavelet method for estimating average tree height and achieved good results. The wavelet method focuses on peak identification under multi-scales and does not limit the number of peaks. Therefore, the wavelet method can be a useful complement to the GLA14 product when it identifies stronger peaks located after the last Gaussian mode or before the first Gaussian mode.

Second, given the unexpectedly short lifetime of the laser system, the GLAS mission started to operate with a 91-day repeat orbit (with a 33-day subcycle) (Sun et al., 2008). In each of the years of operation, GLAS acquired data in February-March, May-June, and October-November (Lee et al., 2011). Many researchers have determined that the GLAS data acquisition time could influence forest canopy height estimation or other waveform parameters (Duong et al., 2008; Neuenschwander et al., 2008; Pang et al., 2008). However, we believe that previous studies on mapping global forest height did not properly constrain/control the observation time of GLAS data. Some researchers used data acquired in a short period of time (Simard et al., 2011), whereas others used data acquired over several years (Lefsky, 2010; Los et al., 2011). When trees do not have leaves, canopy energy can be weakened and canopy return can be shifted toward the ground return, thus resulting in decreased forest canopy height. A reasonable approach is to not use GLAS data from the leaf-off season for non-evergreen forests.

Third, the anisotropic information contained in multi-angle spectral reflectance should be more related to forest structure (Sandmeier et al., 1998; Schull et al., 2007). Although a shadow-affected spectral signal is related to tree height, spectral data still cannot provide explicit information on canopy three-dimensional structure (Chopping et al., 2008, Chopping, 2011). Wang et al. (2011) examined the capability of the MODIS BRDF product to estimate the height of the Harvard forest with directional escape probabilities and suggested that multi-angular observations of MODIS have the potential to be used synergistically with GLAS data. However, to our knowledge, no researcher has combined MODIS BRDF data and GLAS data to map global forest canopy height. It is very essential to test the utility of BRDF data in height modeling.

Fourth, many studies have found that tall or short trees are challenging to map (Nelson, 2010; Simard et al., 2011). This phenomenon could be caused by low correlations between ancillary data and extreme tree height (Simard et al., 2011) and/or by the reduced capability of measuring extreme height with the GLAS waveform (Nelson, 2010). The training algorithm could also be a factor. The objective function of most training algorithms is to minimize the overall error, resulting in a sacrifice in the prediction accuracy of tall or short trees because they usually account for a relatively small percentage of the total. Another consequence is narrow data ranges and small data variations in model predictions. Balanced random forest (BRF), a variant of random forest (RF), can effectively learn from imbalanced data through a sampling technique (Chen et al., 2004). In this study, we used BRF in an attempt to achieve high modeling accuracy and preserve data variation well. 
Finally, there are many different height metrics in forestry. Previous studies have mapped maximum forest height (Simard et al., 2011) and Lorey's height (Lefsky, 2010). However, the mean height of dominant and codominant trees has not yet been mapped globally. Deriving a global map of mean forest canopy height is very useful because of its importance for complementing other height metrics to characterize canopy vertical structure (Chen, 2010), as well as for building the height-biomass relationship (Lefsky et al., 2001; Helmer \& Lefsky, 2006; Simard et al., 2006; Lefsky et al., 2007; Pflugmacher, 2007; Tian et al., 2012).

The primary objective of this study was to produce a global map of mean forest canopy height at a spatial resolution of $500 \mathrm{~m}$. To address the issues, we refined our results as follows: (1) The wavelet method was used to complement the GLA14 product to avoid missing important waveform peaks as much as possible. (2) The seasonal effect on the GLAS mean forest canopy height for different forest types was analyzed to guide the selection of data observation time. (3) The anisotropic factor (ANIF) provided by the MODIS BRDF product (MCD43A1) was included as an ancillary variable for modeling mean forest canopy height. (4) The BRF algorithm was used for model training.

\section{Data and methods}

\subsection{GLAS data filtering}

GLAS data (GLA01 and GLA14, release version 31) that were acquired in 2005 and 2006 were used in the study. The details of the observation campaign over the two years are shown in Table 1. GLA01 stores transmitted and received waveforms from the altimeter, and GLA14 records Gaussian decomposition results (Hofton et al., 2000), geo-location, and other information. These two datasets are linked by the record index (Chen, 2010). To obtain GLAS data of high quality, several filters were designed and implemented.

\subsubsection{Test on noise and the number of peaks}

Noisy GLAS data were excluded. To identify GLAS data with low noise, the maximum return value in GLA01 should be larger than 20 times the background standard deviation and larger than twice the background mean (Baccini et al., 2012; Selkowitz et al., 2012). To ensure that the GLAS waveform is more likely to be reflected by forest canopy, only the GLAS data with at least two Gaussian peaks were retained (Simard et al., 2011; Baccini et al., 2012).

\subsubsection{Land cover test}

GLAS data were geo-registered with the MODIS land cover map (MCD12 product in 2006, version 5), and only those GLAS data from forested sites were retained. Forest classes included evergreen broadleaf forest (EBF), evergreen needleleaf forest (ENF), deciduous broadleaf forest (DBF), deciduous needleleaf forest (DNF), and mixed forest (MF). To minimize the effect of land cover heterogeneity, only pixels having the same forest type as their eight nearest neighbors were retained.

\subsubsection{Elevation test}

Waveforms data were excluded if the difference between the elevation measured by GLAS and the elevation indicated by the ASTER Global Digital Elevation Model (ASTER GDEM, V2) was greater than $70 \mathrm{~m}$. This method has been a common practice in many studies because it can

Table 1

Information of observation campaigns during 2005-2006.

\begin{tabular}{lll}
\hline Observation campaign & Beginning time & Ending time \\
\hline L3b & $2005 / 02 / 17$ & $2005 / 03 / 24$ \\
L3c & $2005 / 05 / 20$ & $2005 / 06 / 23$ \\
L3d & $2005 / 10 / 21$ & $2005 / 11 / 24$ \\
L3e & $2006 / 02 / 22$ & $2006 / 03 / 28$ \\
L3f & $2006 / 05 / 24$ & $2006 / 06 / 26$ \\
L3g & $2006 / 10 / 25$ & $2006 / 11 / 27$ \\
\hline
\end{tabular}

detect data with low signal-to-noise ratio or cloud contamination (Chen, 2010; Lee et al., 2011; Selkowitz et al., 2012; Simard et al., 2011; Baccini et al., 2012).

\subsubsection{Slope test}

With the use of ASTER GDEM data (V2), the slope was calculated as the mean of the slopes of the grid cell for which the GLAS measurement was collected and each of its eight surrounding neighbors. Only GLAS data with a slope of less than $7^{\circ}$ were used because previous studies have shown that forest canopy height can be determined accurately from GLAS data for only a flat region (Neuenschwander et al., 2008; Rosette et al., 2008; Baghdadi et al., 2013). In the study of Simard et al. (2011), which used SRTM DEM data, the slope threshold was set to $5^{\circ}$. However, the spatial resolution of ASTER GDEM data is higher than that of SRTM DEM ( $30 \mathrm{~m}$ vs. $90 \mathrm{~m}$ ). Thus, the threshold condition is too stringent if it is set to $5^{\circ}$. We chose $7^{\circ}$ as the threshold to maintain sufficient GLAS data while limiting slope distortion.

\subsubsection{Test on bias and reconstruction accuracy}

According to the criterion proposed by Simard et al. (2011), only the GLAS data for which maximum tree height (RH100) was greater than four times the bias correction [Df $\times \tan$ (slope)] were preserved. This filter eliminates low height values with high uncertainty. We also used the Gaussian components of GLA14 to reconstruct the original waveforms, and the data with reconstruction accuracy $\left(R_{a}^{2}\right.$, calculated by the $r$ squared value between reconstructed waveform and raw waveform) below 0.80 were removed. This filter removes large height values with high uncertainty.

\subsection{Mean forest canopy height retrieval from GLAS data}

\subsubsection{Determination of the peak distance}

Most studies have used the distance between signal beginning and ground peak (often denoted as RH100) to estimate maximum forest canopy height. Given that this study focuses on mean forest canopy height, we extracted peak distance, which is defined as the distance between the first and last Gaussian peaks, from the GLA14 product. The last Gaussian peak indicates the mean elevation of the ground return, and the first peak corresponds to the centroid of the uppermost canopy layer (Harding and Carabajal, 2005; Duong, et al., 2008). Thus, peak distance is indicative of the mean height of the dominant and codominant trees (Lefsky et al., 2007; Wang et al., 2013). Given that GLA14 provides only as many as six modes, the first or the last peak could be missed, particularly when the forest has a complex vertical structure. For example, strong peaks exist beyond the locations of the six Gaussian components (Fig. 1a), which could result in underestimation of forest canopy height for the EBF case. As mentioned in Section 1.3, it is risky to rely only on GLA14 data.

The wavelet method proposed by Wang et al. (2013) identifies waveform peaks through wavelet transformation. The method includes two steps. First, waveform peaks are extracted by applying Marr wavelet functions at five scales $(2,4,8,16$, and 32$)$. Then, considering the intensity and the symmetry of peaks at different scales, the best locations of the peaks are determined. The wavelet method can capture more than six peaks and is thus effective for processing waveforms with many modes. However, the wavelet method easily misses gentle peaks for relatively simple waveforms because it does not decompose the waveform [see Fig. 1 (bc)]. Our preliminary analysis showed that the wavelet method has a clear tendency to underestimate mean forest canopy height, excluding EBF with complicated waveforms. To address such problems, we designed a new procedure combining the results of Gaussian fitting and the wavelet method, with the goal of preventing important peaks from being missed. Four steps are included in this procedure.

(1) The first and last peaks are extracted from the GLA14 product.

(2) The wavelet method is applied to GLA01 data to identify the first and last peaks. 


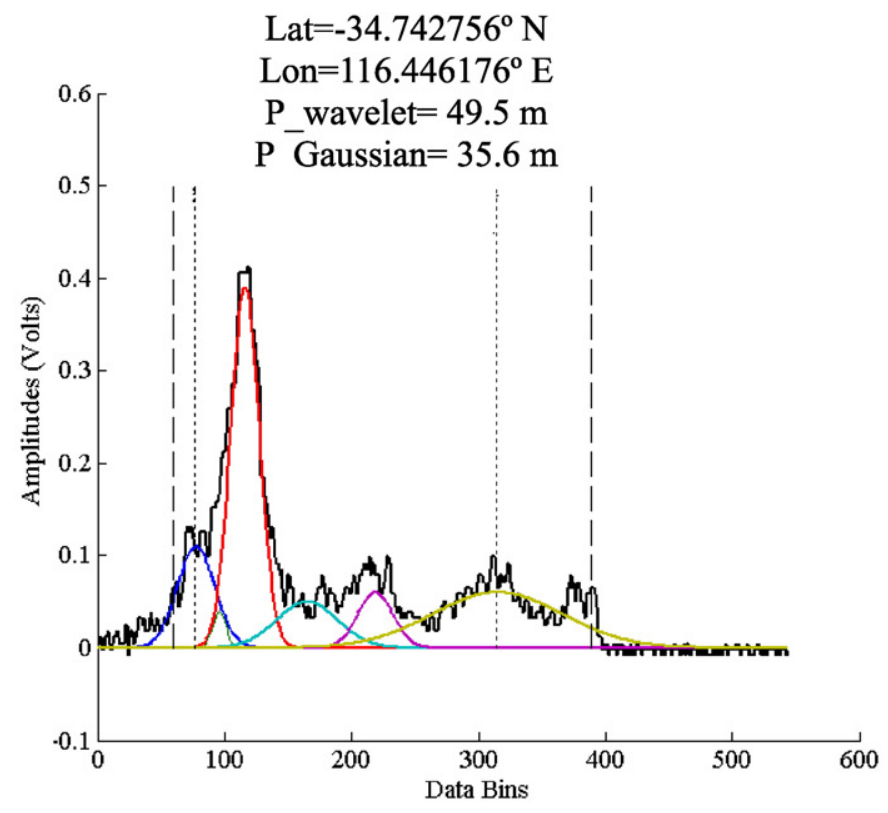

(a)

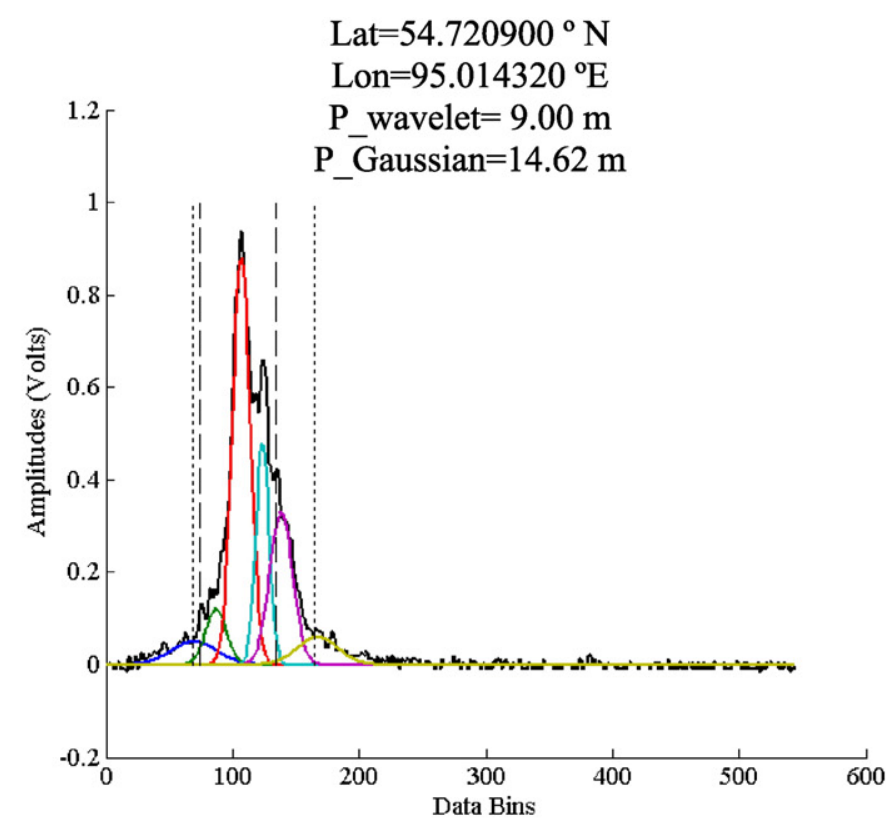

(b)

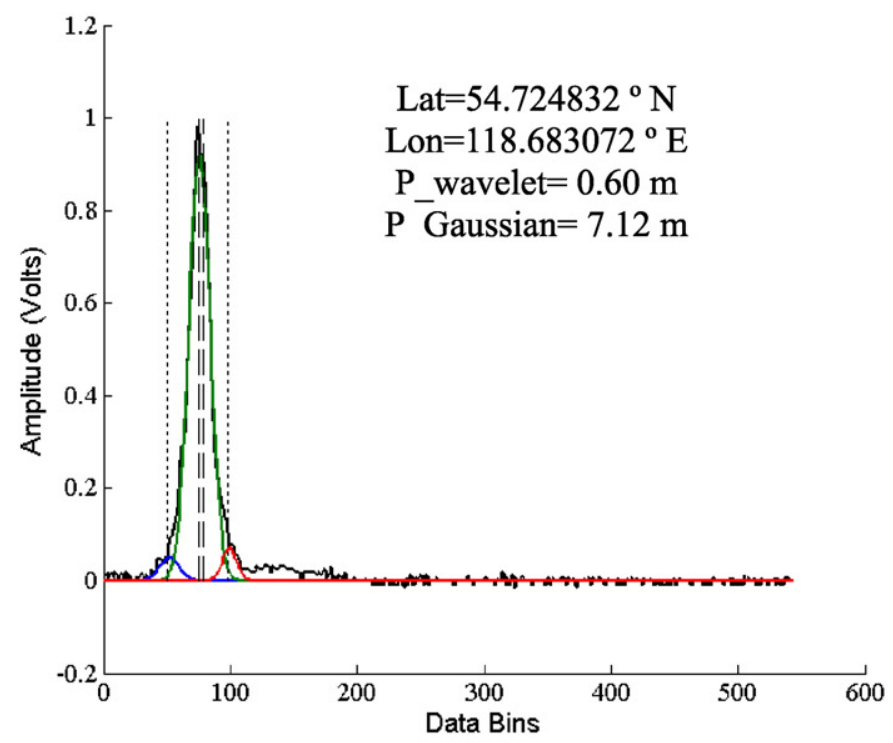

(c)

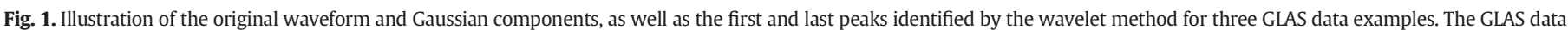

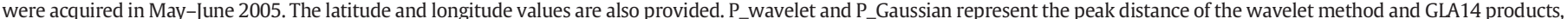

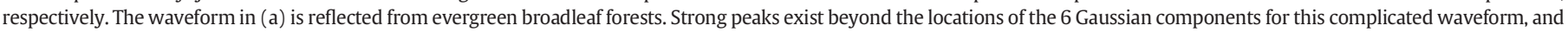

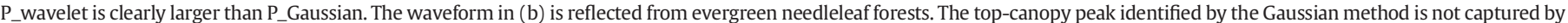

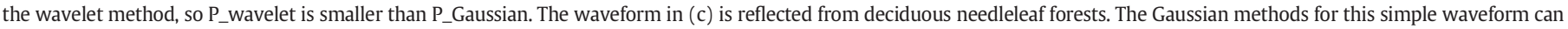
identify subtle peaks through waveform decomposition, whereas the wavelet method cannot capture these peaks, so P_wavelet is significantly smaller than P_Gaussian.

(3) If the amplitude of the first (last) wavelet peak is clearly larger than that of the first (last) Gaussian peak, and the location of the first (last) wavelet peak appears earlier (later), then the first (last) Gaussian peak is replaced by the first (last) wavelet peak. The amplitude difference threshold is set to $0.02 \mathrm{~V}$.

(4) The distance between the first and last peak determined in Step 3 is calculated.

\subsubsection{Height retrieval of GLAS data}

Either a direct or a statistical method can be used to obtain forest canopy height from GLAS waveform parameters (Chen, 2010). The statistical method requires topographic information from ancillary DEM data to derive a correction model (Lefsky et al., 2005; Rosette et al., 2008; Chen, 2010). The model is usually site-specific and heavily dependent on the selection of training data, thus it results in a large bias when applied to global-level GLAS data. More importantly, the accuracy of the conventional DEM data over forested areas is often inadequate, which sometimes results in poor estimation of forest canopy height (Lefsky et al., 2007; Chen, 2010; Baghdadi et al., 2013). Lee et al. (2011) recently proposed a physically based method of retrieving vegetation structure by assuming homogeneous canopy height within the footprint. Their study site was the southern portion of White Mountain National Forest in New Hampshire, USA, which is a region characterized by old-growth northern hardwoods. Although the physically 
Table 2

List of ancillary variables used.

\begin{tabular}{|c|c|c|c|c|c|}
\hline & Variable code & Variable name & Dataset & Year & Reference \\
\hline \multirow[t]{7}{*}{ Climatic variables } & 1 & Mean temperature & Worldclim & $1950-2000$ & Hijmans et al. (2005) \\
\hline & 2 & Temperature seasonality & Worldclim & $1950-2000$ & Hijmans et al. (2005) \\
\hline & 3 & Temperature range & Worldclim & $1950-2000$ & Hijmans et al. (2005) \\
\hline & 4 & Mean precipitation & Worldclim & $1950-2000$ & Hijmans et al. (2005) \\
\hline & 5 & Precipitation of wettest month & Worldclim & $1950-2000$ & Hijmans et al. (2005) \\
\hline & 6 & Precipitation of driest month & Worldclim & $1950-2000$ & Hijmans et al. (2005) \\
\hline & 7 & Precipitation seasonality & Worldclim & $1950-2000$ & Hijmans et al. (2005) \\
\hline \multirow[t]{6}{*}{ Remote sensing variables } & 8 & Annual mean NBAR at red band & MCD43A1 & 2006 & Schaaf et al. (2002) \\
\hline & 9 & Annual mean NBAR at NIR band & MCD43A4 & 2006 & Schaaf et al. (2002) \\
\hline & 10 & Annual mean ANIF & MCD43A4 & 2006 & Schaaf et al. (2002) \\
\hline & 11 & Tree fraction & MOD44B & 2006 & Hansen et al. (2003) \\
\hline & 12 & Annual accumulated EVI & MOD13A1 & 2006 & Huete et al. (2002) \\
\hline & 13 & DEM & SRTM, GTOPO & 2000 & U.S. Geological Survey (2006) \\
\hline
\end{tabular}

based method is promising for global-scale application, we did not use it in this study for several reasons. First, the model still requires parameterization (Lee et al., 2011; Selkowitz et al., 2012), and it has not been evaluated fully in regions and biomes other than those of the study of Lee et al. (2011). Second, a heterogeneous forest canopy within a GLAS footprint could be overcompensated (Simard et al., 2011) because of the simple assumption of uniform tree height. Finally, the method is designed for maximum height estimation, whereas our focus is mean forest canopy height.

This study applied a direct method, in which the peak distance was used as the mean forest canopy height. The reasons for this choice follow: (1) GLAS data with a slope of more than $7^{\circ}$ were not used, so the slope distortion was very small. Baghdadi et al. (2013) tested different methods for estimating forest canopy height in Eucalyptus plantations in Brazil, and they found that the direct method was nearly as accurate as statistical methods for their slightly sloping study site $\left(<7^{\circ}\right)$. In addition to the slope test, we retained only the GLAS data for which maximum forest canopy height was dramatically larger than the bias correction, which further decreased the slope effect on GLAS height retrieval. (2) The influence of slope on mean forest canopy height is not as strong as that for maximum forest canopy height because the leading edge, which is a measure of canopy surface variability and surface relief (Hilbert and Schmullius, 2012; Baghdadi et al., 2013), is not included in the peak distance. (3) The topographic correction required to estimate mean forest canopy height is often significantly lower than what is expected from the local slope because a large part of the ground surface is not recorded in the waveform (Lefsky et al., 2007; Hilbert and Schmullius, 2012).

\subsection{Seasonal variation of GLAS mean forest canopy height}

GLAS data were collected over three periods (May-June, FebruaryMarch, and October-November) per year. Although the seasonal pattern varies with latitude, considering May-June as the growing season and the other two periods as the dormant season is valid for most regions in the Northern Hemisphere. To highlight the seasonal variations statistically, we calculated the mean, standard deviation (std), and coefficient of variation (CV) of GLAS mean forest canopy height for each period.

Given that the statistical comparison was not spatially explicit, we performed spatial analysis of the seasonal effect, which could be related to forest type, climatic features, dominant tree species, and other factors. First, we produced two height maps at a spatial resolution of $0.5^{\circ} \times 0.5^{\circ}$ for May-June and February-March, respectively, by averaging all the filtered GLAS data for each grid. Then, we calculated a height difference map between the two periods to show the geographic distribution of the seasonal effect. Although the grid size was coarse, this grid size can decrease the occurrence of data gaps caused by the low density of GLAS, and it is used commonly for climatic and ecological models.

\subsection{Ancillary data processing}

The selection of ancillary data influences mapping performance, and the correlation between these data and forest height is a major consideration. After experimentation, 13 ancillary variables, including seven climatic variables, five MODIS remote sensing products, and elevation data, were selected (Table 2). The MODIS products of year 2006 were used because of their temporal overlap with GLAS data.

\subsubsection{Climatic and elevation data}

WorldClim data are a set of global climate layers (from 1950 to 2000) with a spatial resolution of $\sim 1 \mathrm{~km}$. The maps were generated with data from a network of more than 4000 weather stations worldwide (Hijmans et al., 2005), and these maps were spatially interpolated using elevation from the SRTM and latitude as covariables. This bioclimatic dataset (version 1.4) was used in our study. From this dataset, seven variables were selected (mean temperature, temperature seasonality, temperature range, mean precipitation, precipitation of wettest month, precipitation of driest month, and precipitation seasonality) to explore their relationships with GLAS mean forest canopy height. The climatic maps were interpolated to a resolution of $500 \mathrm{~m}$ for consistency with remote sensing data using the nearest neighbor resampling method.

Although elevation information was used to produce the WorldClim data, elevation data were still included as an ancillary variable to account for the influence of elevation on forest characteristics.

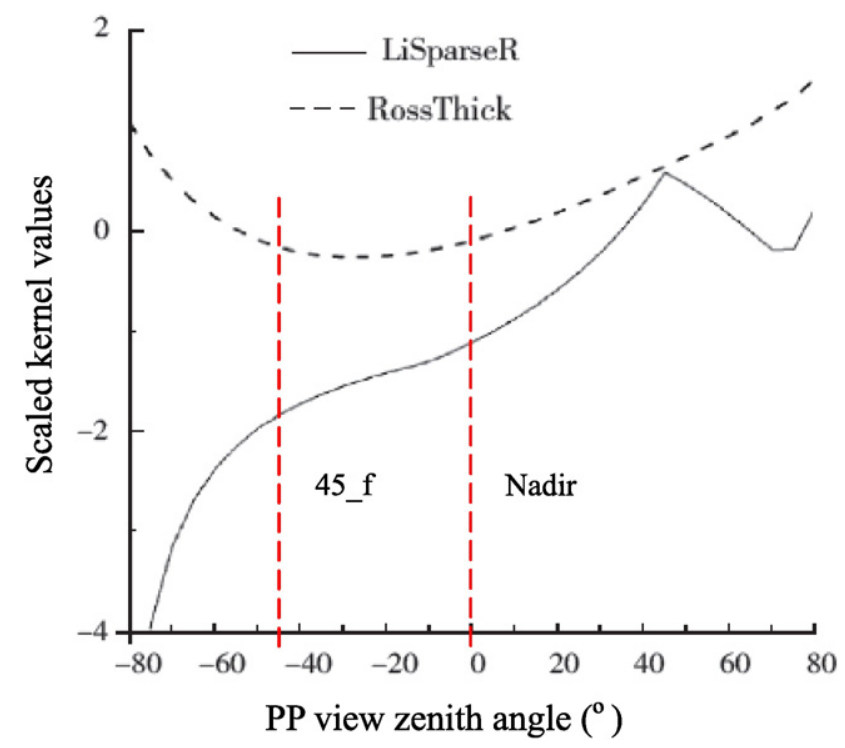

Fig. 2. Principal plane (PP) plots of the RossThick and LiSparse-R BRDF model kernel values (after Jiao et al., 2011). 
Table 3

The data volume of original GLAS data (GLA14 product) and the cumulative percentage of data removed by subsequent filters, using the Asian region $\left(15-55^{\circ} \mathrm{N}, 70-135^{\circ} \mathrm{E}\right)$ data acquired in May-June 2005 as an example.

\begin{tabular}{lcc}
\hline & $\begin{array}{l}\text { The number of } \\
\text { GLAS shots }\end{array}$ & $\begin{array}{l}\text { Cumulative percentage (\%) } \\
\text { of data removed }\end{array}$ \\
\hline Original data & $2,425,961$ & 0 \\
After test on num_peak and noise & 946,276 & 60.9938 \\
After land cover test & 90,775 & 96.2582 \\
After DEM test & 86,739 & 96.4246 \\
After slope test & 30,418 & 98.7461 \\
After bias test & 19,136 & 99.2112 \\
After reconstruction accuracy test & 18,728 & 99.2280 \\
\hline
\end{tabular}

\subsubsection{MODIS BRDF product (MCD43A1, MCD43A4)}

The MODIS BRDF product (MCD43A1) provides two types of information: (a) weighting parameters associated with the semi-empirical BRDF model (RossThick-LiSparse reciprocal kernel-driven BRDF model) that best describe the reflectance anisotropy of each $500 \mathrm{~m}$ pixel, and $(b)$ shape indicators constructed with reflectance values in typical scattering angles (such as hotspot, dark spot, and zenith). The weights associated with the kernels do not have a direct relationship with biophysical parameters. Moreover, these weights are sensitive to observation geometries, noise, and the number of observations (Gao et al., 2003). Therefore, this study mainly explored the relationship between shape indicators and forest canopy height. Four shape indicators are included in the MCD43A1 product. Among these indicators, ANIF (anisotropic factor) was selected because it demonstrated a high correlation with mean forest canopy height in our preliminary work. ANIF is the ratio of NIR reflectance at nadir to that at $45^{\circ}$ forward scattering with a $45^{\circ}$ sun zenith angle. A stronger geometric optical effect results in a larger ANIF value (Fig. 2). Given that shape indicators are only applied to pixels with full inversion, many data gaps exist in the MCD43A1 products. Annual means of ANIF were calculated to fill the gaps and used as input for model training. Shape indicators do not contain spectral information. Thus, we also included the annual mean value of NBAR (Nadir BRDF-Adjusted Reflectance) at red and the NIR band from the MCD43A4 product.

\subsubsection{MODIS percent tree cover product (MOD44B)}

The Vegetation Continuous Fields collection (MOD44B) contains proportional estimates for woody vegetation cover types (Hansen et al., 2002, 2003). A regression tree algorithm is used to predict tree cover based on multi-temporal metrics of a full year, with a reported RMSE of 9.06\%. This product was included as an ancillary variable considering the strong correlation between forest canopy height and coverage.

\subsubsection{Accumulated EVI}

The accumulated vegetation index has been determined to be useful in biomass mapping by previous studies (Dong et al., 2003; Li et al., 2011). Thus, we calculated the annual accumulated Enhanced Vegetation Index (EVI) above 0.1 from MOD13A1 and used it as ancillary data.

\subsection{Mean forest canopy height modeling process}

\subsubsection{Construction of training data}

All of the ancillary data were re-sampled to a spatial resolution of $500 \mathrm{~m}$ and georegistered with the GLAS data. If the pixels encompassed the centroid of only a single GLAS shot, the GLAS height was used to represent the entire pixel. Additionally, if the pixel encompassed two or more GLAS shots, the mean GLAS height was used to represent the pixel. If the GLAS heights within one pixel showed extreme variation, then mean values, excluding outliers beyond three standard deviations from the mean, were used. The number of training samples was approximately 0.92 million, which was smaller than the number of filtered GLAS data points because of pixel aggregation.

The training data included only the GLAS data with slope angles of less than $7^{\circ}$. However, the prediction model was applied to areas with steep slopes (Simard et al., 2011). This was not to deny the relationship between tree height and slope, but to accept the reasonable assumption that the tree heights at two locations are the same if they share the same ancillary variables, regardless of slope. If slope was specifically included in the ancillary variable list, it would be dangerous to apply a model that could handle only slopes of less than 7 degrees to steep regions with slopes greater than 7 degrees. However, only climatic, elevation, and RS (Remote Sensing) factors were used as ancillary variables when building the model. If these variables are well represented in the training dataset, it is not very risky to apply the model to steep regions given that the climatic, elevation, and RS factors over steep regions are not beyond the extent defined in the training dataset. Another reason that slope was not included in the model is that the strong relationship between GLAS tree height and slope easily distorts the relationship between GALS data and ancillary variables (climatic, RS, and DEM), which further results in an inferior model.

\subsubsection{Description of training algorithm}

The BRF algorithm was selected for model training. This algorithm is a variant of RF, which is an ensemble of unpruned classification or regression trees induced from bootstrap samples of the training data (Breiman, 2001). The uniqueness of RF is that at each node, the splitting rule is obtained by searching a set of randomly selected variables instead of searching through all variables. Such randomness in tree induction can enhance ensemble diversity and thereby further improve prediction accuracy. A prediction is made by aggregating the predictions of the ensemble. The RF generally exhibits substantial performance improvement over a single tree classifier (Chen et al., 2004). Moreover, RF has good generalization ability, which compares favorably to that of AdaBoost (another ensemble strategy), yet is more robust to noise. Despite its outstanding merits, RF cannot perform well when the training dataset is extremely imbalanced, as is the case with most classifiers. Two solutions have been proposed to mitigate this problem: BRF and weighted random forest. Chen et al. (2004) determined that BRF performs efficiently, so we applied BRF in this study.

The BRF model was developed for each of seven geographic regions, approximately corresponding to North America, South America, Europe, Africa, Asia, Australasia, and Siberia. Before proceeding with model

Table 4

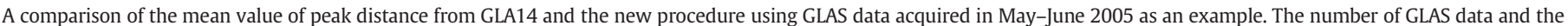
percentage of GLAS data with a peak distance different from the GLA14 products are also shown.

\begin{tabular}{|c|c|c|c|c|}
\hline & $\begin{array}{l}\text { Peak distance from GLA14 } \\
(\mathrm{m})\end{array}$ & $\begin{array}{l}\text { Peak distance from new } \\
\text { procedure }(\mathrm{m})\end{array}$ & $\begin{array}{l}\text { The number of GLAS } \\
\text { shots }\end{array}$ & $\begin{array}{l}\text { The percentage (\%) of GLAS data with } \\
\text { peaks from wavelet method }\end{array}$ \\
\hline Evergreen needleleaf forest & 17.09 & 17.17 & 56,997 & 5.01 \\
\hline Evergreen broadleaf forest & 26.90 & 27.46 & 274,636 & 18.87 \\
\hline Deciduous needleleaf forest & 16.37 & 16.40 & 38,046 & 4.04 \\
\hline Deciduous broadleaf forest & 20.36 & 20.54 & 16,884 & 8.37 \\
\hline Mixed forest & 20.77 & 20.84 & 87,058 & 4.81 \\
\hline All the forests & 23.51 & 23.87 & 473,621 & 13.05 \\
\hline
\end{tabular}




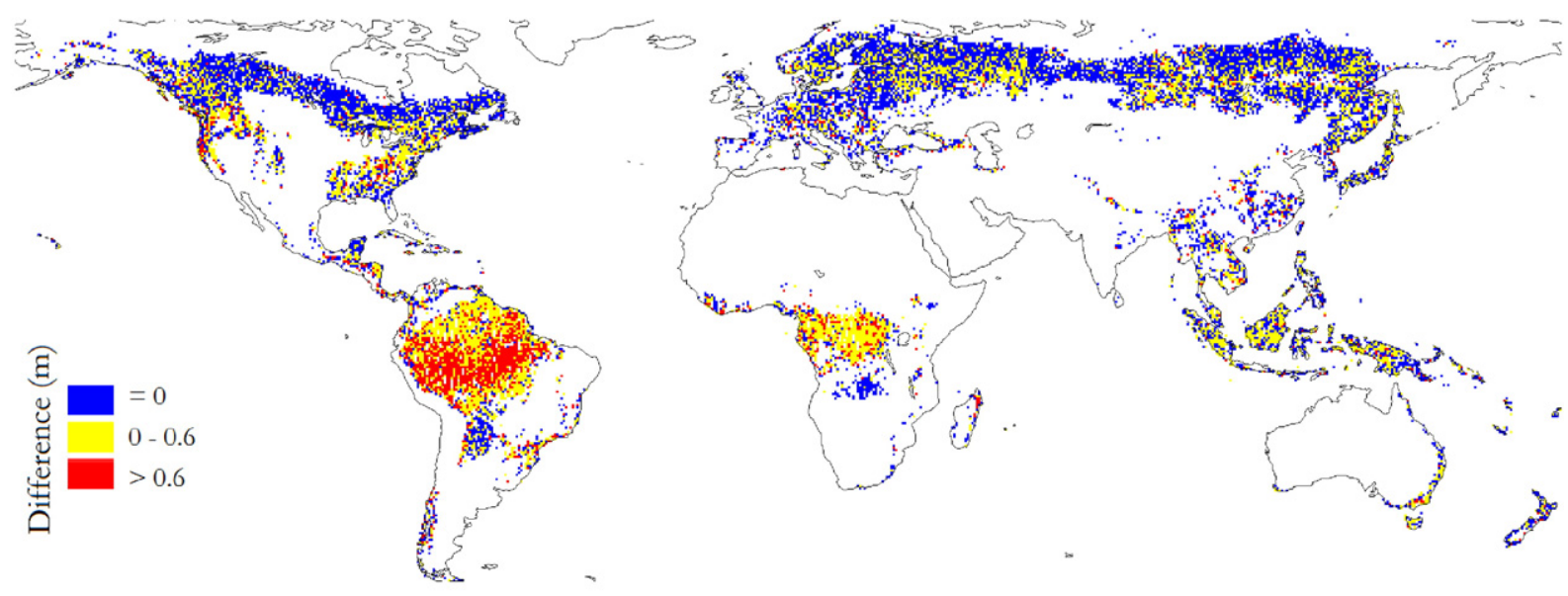

(a) Differences in peak distance

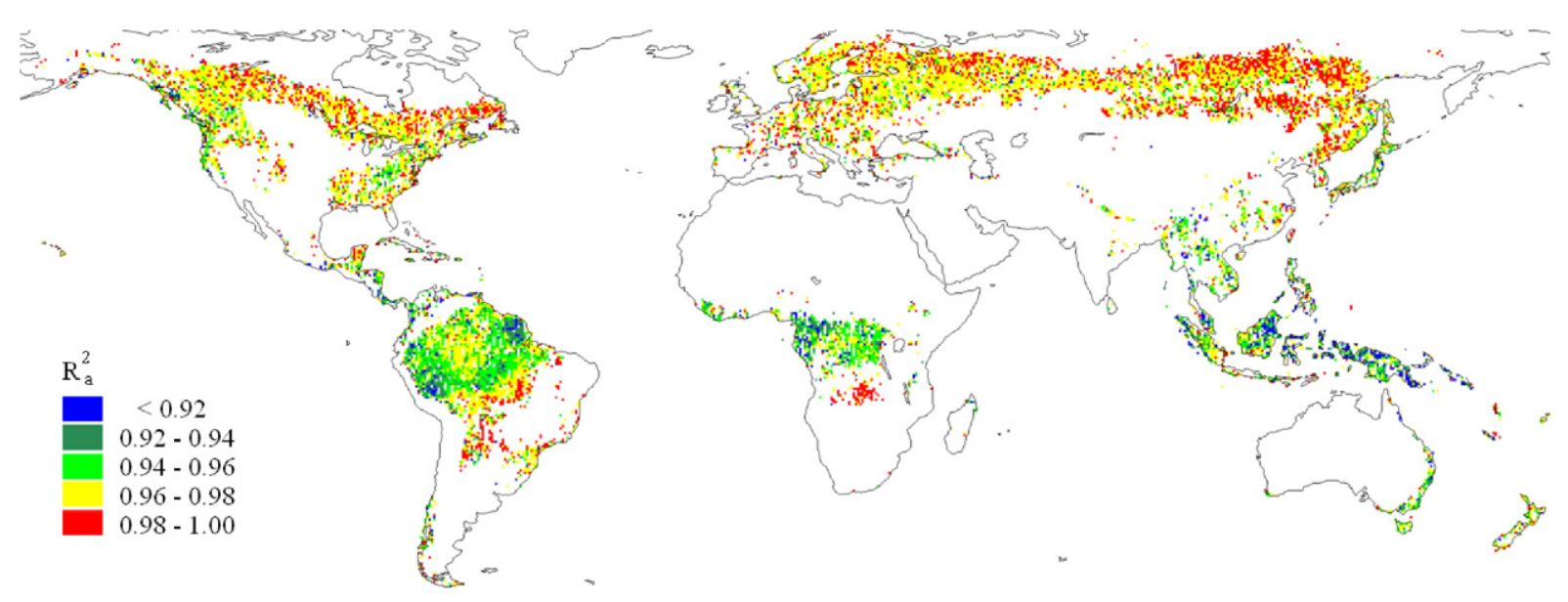

(b) Reconstruction accuracy

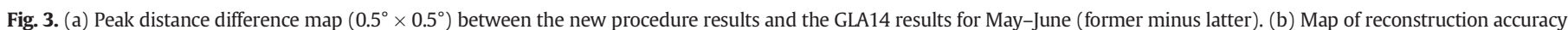

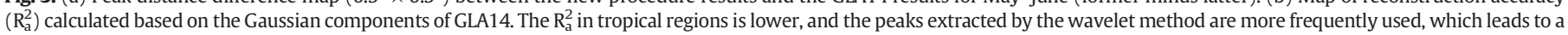
larger difference in the peak distances between the new procedure results and the GLA14 results.

training, forest height was sorted from short to tall and then divided into seven groups (G1, G2,..., G7). The dividing points were automatically determined to make the number of elements in each group show a

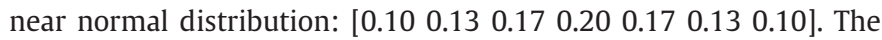
groups in the middle position (G3, G4, G5) represent trees of medium height (majority classes), whereas the groups at both ends ( $\mathrm{G} 1, \mathrm{G} 3$, G6, G7) represent short or tall trees (minority classes). The same number of cases was sampled with replacement from each group to constitute a balanced training dataset for building a regression tree. In our study, the sample size was set to the number of elements in G4. Thus, the majority classes were undersampled, and the minority classes were oversampled. The information loss caused by the undersampling of the majority classes can be solved by training more regression trees. Two hundred regression trees were built for each geographic region, and the outputs of these regression trees were aggregated by averaging. The minimum size of a leaf node in the regression trees was set to five observations, and the number of variables selected at random for each decision split was set to four.

Table 5

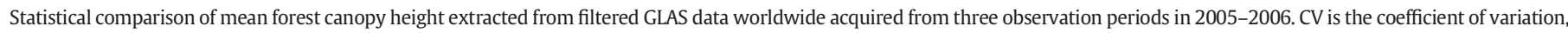
defined as the division of standard deviation and mean. The figure after the month is the number of filtered GLAS data.

\begin{tabular}{|c|c|c|c|c|c|c|c|c|c|}
\hline & \multicolumn{3}{|c|}{ May-June $(946,251)$} & \multicolumn{3}{|c|}{ February-March $(659,188)$} & \multicolumn{3}{|c|}{ October-November $(682,591)$} \\
\hline & Mean $(\mathrm{m})$ & Std $(\mathrm{m})$ & $\mathrm{CV}(\%)$ & Mean $(\mathrm{m})$ & Std $(\mathrm{m})$ & $\mathrm{CV}(\%)$ & Mean $(\mathrm{m})$ & Std $(\mathrm{m})$ & $\mathrm{CV}(\%)$ \\
\hline Evergreen needleleaf forest & 17.34 & 7.05 & 40.65 & 17.16 & 7.68 & 44.73 & 17.48 & 7.71 & 44.12 \\
\hline Evergreen broadleaf forest & 27.36 & 7.54 & 27.56 & 27.31 & 7.94 & 29.07 & 26.87 & 7.55 & 28.08 \\
\hline Deciduous needleleaf forest & 16.44 & 6.30 & 38.31 & 14.28 & 6.91 & 48.37 & 15.11 & 6.95 & 46.00 \\
\hline Deciduous broadleaf forest & 20.26 & 7.26 & 35.81 & 17.58 & 7.63 & 43.39 & 19.69 & 8.10 & 41.13 \\
\hline Mixed forest & 20.80 & 6.21 & 29.87 & 18.04 & 7.30 & 40.46 & 19.35 & 7.27 & 37.57 \\
\hline
\end{tabular}




\subsubsection{Analysis of variable importance}

Quantification of variable importance can be realized by measuring the increase in prediction error that occurs if the values of such a variable are permuted across the out-of-bag observations (Genuer et al., 2010). For each variable, the error increment is computed for every tree, averaged over the entire ensemble, and divided by the standard deviation over the entire ensemble. Many recent studies demonstrated that the permutation variable importance tends to overestimate the importance of correlated predictor variables, and a new type of measurement, namely conditional variable importance, derived from the conditional inference forest was proposed (Strobl and Zeileis, 2008; Nicodemus et al., 2010).

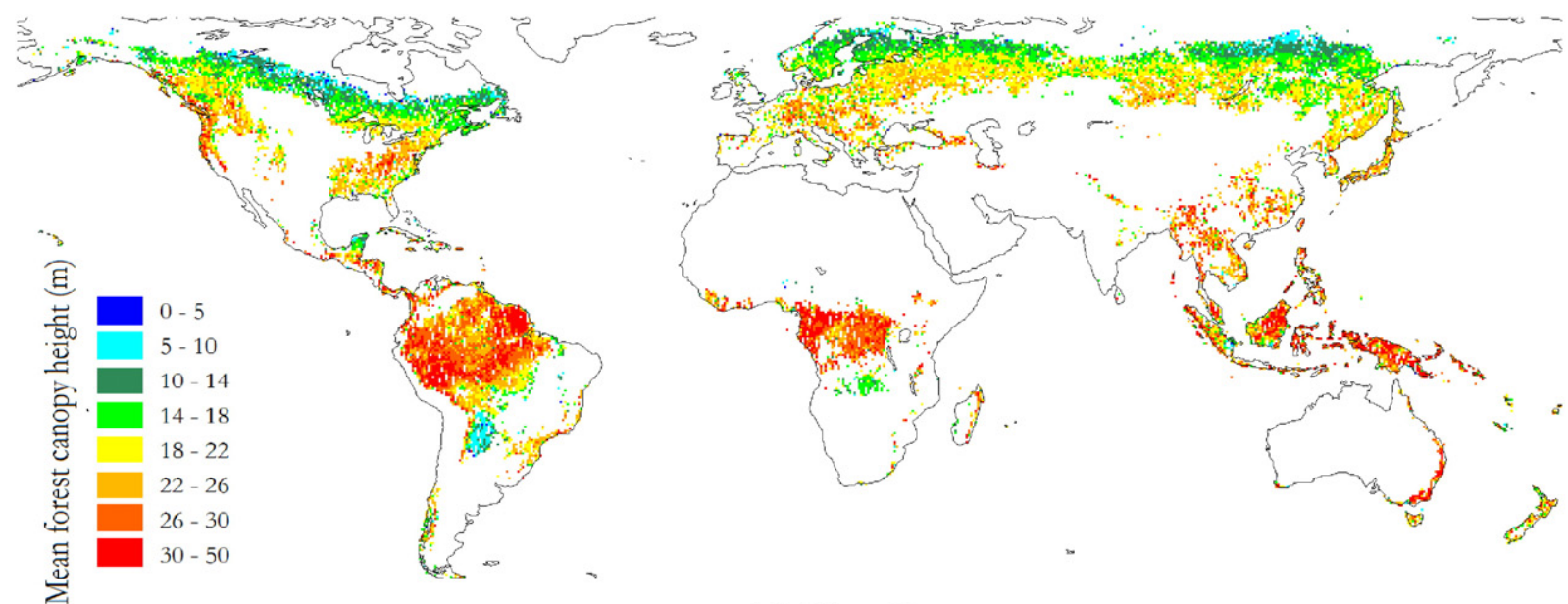

(a) May-June

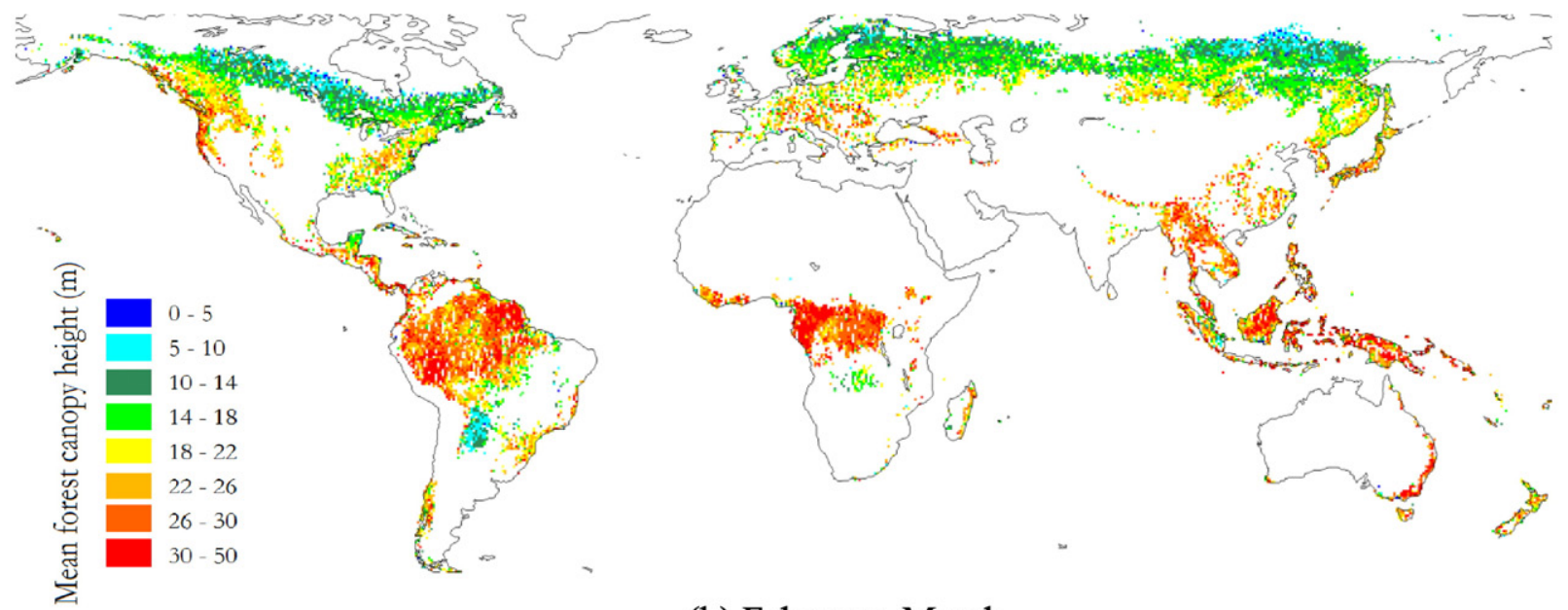

(b) February-March

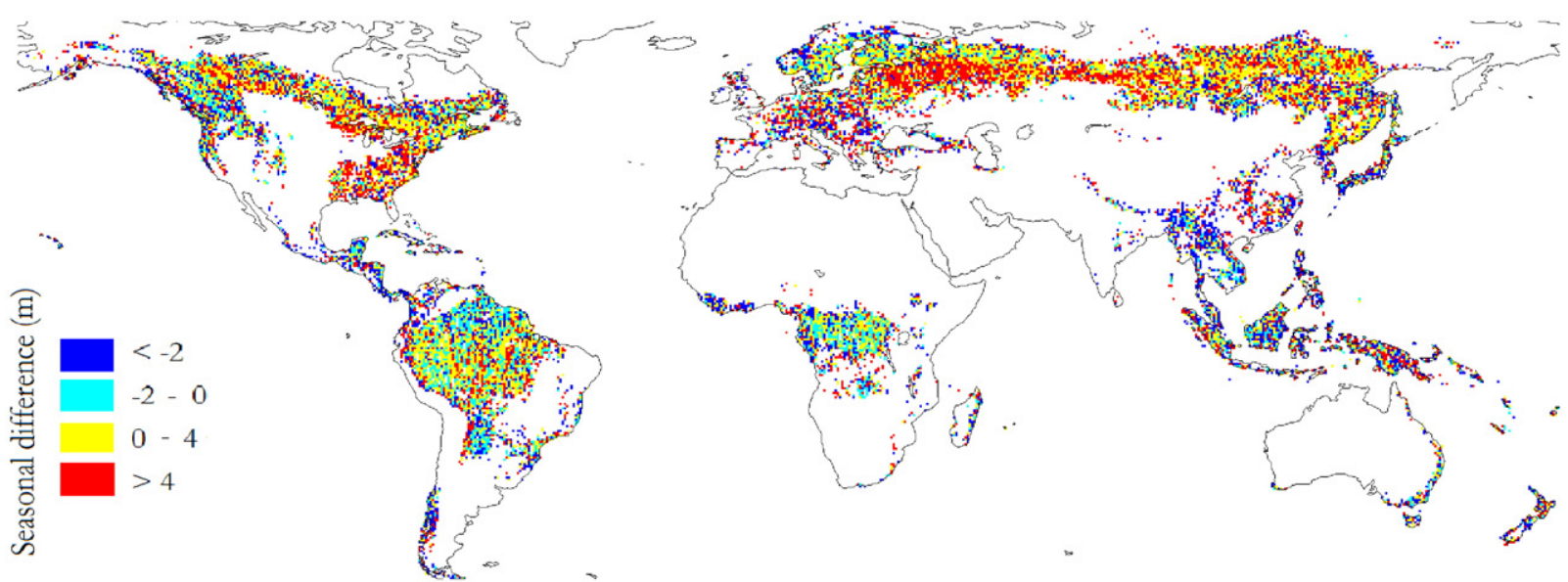

(c) Seasonal difference (a minus b)

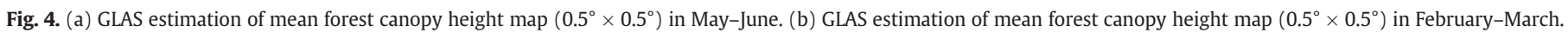
(c) Seasonal difference in mean forest canopy height (a minus b). 
Unfortunately, calculating conditional variable importance is highly time-consuming and computationally intractable for large volumes of data (Nicodemus et al., 2010). Thus, in this study, the variable importance measures were calculated based on BRF. To reduce the negative influence of variable correlation on variable importance analysis, we adopted a two-stage analysis. According to Nicodemus et al. (2010), decreasing the number of randomly selected features at each splitting node (the parameter mtry) can reduce the risk of overestimating the importance of correlated predictor variables. Therefore, we calculated variable importance values two times, one time with mtry set to 4 (this was also used for height modeling with BRF) and the other with mtry set to 1 . If a variable showed a high importance value (top 7 ranking) under both conditions, it was considered important. There is an assumption behind this analysis. When mtry is set to 4 , variables with high importance values could include truly influential variables as well as variables that are highly correlated with influential variables but do not have a direct effect on the response. When mtry is set to 1 , the variables that are not associated strongly with the response are likely to be assigned lower importance values so that they can be distinguished from truly influential predictors. However, the important variables identified with this method may still be inter-correlated, so we calculated the pair-wise correlation coefficients of variables to assist interpretation.

In addition to variable importance measurement, we evaluated the contribution of RS variables to the height modeling by comparing the accuracy of using climatic variables alone with the accuracy of using both climatic and RS data.

\subsubsection{Result validation and comparisons}

Result validation was implemented in the following two ways:

(a) Validation of GLAS mean forest canopy height retrieval at the footprint level.

To provide accuracy information for mean forest canopy height estimated with GLAS peak distance, 71 field measurements of tree height were acquired in Yunnan and Inner Mongolia, China. These plots were mostly on flat ground. In Yunnan, the forest type at the field survey plot is mostly EBF. In Inner Mongolia, the forest type is mostly DNF and DBF. Each field sample covered an area of $900 \mathrm{~m}^{2}$ centered on a GLAS shot. The heights of all the dominant and codominant trees with a diameter at breast height (DBH) of more than $10 \mathrm{~cm}$ within a plot were measured with a hand-held Blume-Leiss altimeter. The altimeter is based on the principle of triangulation, which uses the angle of elevation from an observer to the top of a subject tree and the distance between the observer and the subject tree (Nakai et al., 2010). To control the measurement error, the distance between the observer and the tree was adjusted according to the tree height, and the top of the tree was carefully identified in the dense forests. The tree height measurements were averaged and compared with the colocated footprint level estimates of the GLAS peak distance.

(b) Validation of the map of mean forest canopy height.

A forest canopy height map with spatial resolution of $500 \mathrm{~m}$ is difficult to directly validate through field observations. Plotscale inventory cannot be used unless the forest is uniform and homogenous. Additionally, comprehensive field measurements at scales of $500 \mathrm{~m}$ and above are too expensive for ecologists to undertake (Song et al., 2010; Chopping, 2011). In this study, we used data that were freely available from the Oak Ridge National Laboratory Distributed Active Archive Center (ORNL DAAC) for biogeochemical dynamics. These data are reliable, spatially representative, and have been studied intensively in previous work. Most importantly, many field observations of forest height are local, which is highly appropriate for validation of forest height at a spatial resolution of $500 \mathrm{~m}$. We also obtained some global FLUXNET data on the DAAC website for which representative forest height can be used because of spatial homogeneity.

\section{Analysis of result}

\subsection{GLAS data filtering}

Table 3 shows the cumulative percentage of data removed by subsequent filters, using the Asian region data $\left(15-55^{\circ} \mathrm{N}, 70-135^{\circ}\right.$ E) acquired in May-June 2005 as an example. The volume of data decreased substantially after application of the filters. Approximately $99 \%$ of the original GLA14 data was removed, but most of the data (approximately 96\%) were removed because they had low SNR and were reflected from the ocean or from non-forested land. For the remaining GLAS data, which were from forest, the slope test and the bias test were the most stringent filters, which is especially the case for regions with a wide distribution of mountains, such as Asia. More than $70 \%$ of the forest GLAS data was removed because these data were from steep slopes, and the potential broadening of the waveform was large in relation to the GLAS maximum height.

Table 6

Mean forest canopy height modeling performance for different geographic regions.

\begin{tabular}{|c|c|c|c|c|c|c|c|}
\hline & Asia & North America & Africa & South America & Australasia & Siberia & Europe \\
\hline Sample size & 62,732 & 94,095 & 134,288 & 438,751 & 56,269 & 57,195 & 81,434 \\
\hline Mean $(\mathrm{m})$ & 24.09 & 19.70 & 28.23 & 27.06 & 26.91 & 16.43 & 18.89 \\
\hline Std_original (m) & 8.08 & 7.87 & 7.08 & 6.91 & 9.47 & 6.01 & 6.28 \\
\hline BRF_R ${ }^{2}$ & 0.83 & 0.84 & 0.82 & 0.59 & 0.84 & 0.82 & 0.82 \\
\hline RF_R ${ }^{2}$ & 0.79 & 0.82 & 0.78 & 0.57 & 0.81 & 0.80 & 0.80 \\
\hline Dif_R ${ }^{2}(\%)$ & 5.06 & 2.44 & 5.13 & 3.51 & 3.70 & 2.50 & 2.50 \\
\hline BRF_RMSE (m) & 3.66 & 3.22 & 3.30 & 4.45 & 4.09 & 2.75 & 2.85 \\
\hline RF_RMSE (m) & 4.16 & 3.58 & 3.73 & 4.62 & 4.63 & 3.09 & 3.19 \\
\hline Dif_RMSE (\%) & -12.02 & -10.06 & -11.53 & -3.68 & -11.66 & -11.00 & -10.66 \\
\hline BRF_Std (m) & 5.93 & 6.39 & 5.06 & 4.76 & 7.12 & 4.34 & 4.62 \\
\hline RF_Std (m) & 5.24 & 5.83 & 4.56 & 4.31 & 6.39 & 3.87 & 4.14 \\
\hline Dif_Std (\%) & 13.17 & 9.61 & 10.96 & 10.44 & 11.42 & 12.14 & 11.59 \\
\hline Height threshold for short trees (m) & $<15.54$ & $<10.13$ & $<19.35$ & $<18.53$ & $<15.73$ & $<8.33$ & $<10.97$ \\
\hline RMSE_BRF_short (m) & 4.39 & 3.84 & 4.90 & 6.70 & 5.07 & 4.19 & 4.18 \\
\hline RMSE_RF_short (m) & 5.62 & 4.97 & 6.17 & 7.32 & 6.53 & 5.35 & 5.31 \\
\hline Dif_short (\%) & -21.89 & -22.74 & -20.58 & -8.47 & -22.36 & -21.68 & -21.28 \\
\hline Height threshold for tall trees (m) & $>34.30$ & $>29.49$ & $>36.67$ & $>35.14$ & $>38.74$ & $>23.77$ & $>26.49$ \\
\hline RMSE_BRF_tall $(\mathrm{m})$ & 6.66 & 5.11 & 5.40 & 7.56 & 6.93 & 4.07 & 4.42 \\
\hline RMSE_RF_tall (m) & 8.65 & 6.66 & 6.82 & 8.37 & 9.01 & 5.17 & 5.61 \\
\hline Dif_tall (\%) & -23.01 & -23.27 & -20.82 & -9.68 & -23.09 & -21.28 & -21.21 \\
\hline
\end{tabular}


Table 7

Important variables identified in each geographic region model. Variables shown in brackets are highly correlated.

\begin{tabular}{ll}
\hline Regions & Important variables \\
\hline Asia & precipitation seasonality; mean_red; mean_NIR; ANIF; DEM \\
North America & [mean temperature, temperature seasonality]; mean_red; \\
& ANIF; tree cover; DEM \\
Africa & [mean temperature, DEM]; [mean_NIR, accum_evi] \\
South America & [mean temperature, temperature seasonality, DEM]; [mean \\
& precipitation, precipitation of wettest month]; [mean_NIR, \\
& accum_evi] \\
Australasia & precipitation of driest month; precipitation seasonality; \\
tree cover; DEM & [mean_red, mean_NIR]; tree cover; accum_evi; DEM \\
Europeria & [mean_red, tree cover]; mean_NIR; DEM
\end{tabular}

By contrast, the elevation test and the reconstruction accuracy test are not very strict and only affected a small amount of data.

Although a high percentage of GLAS data are removed, the forest area represented by GLAS data does not decrease at the same level because of the exact repeat orbit of the ICESat (Schutz et al., 2005; Fricker \& Padman, 2006). Because numerous GLAS data are very close in either the along-track direction or the cross-track direction, it is more reasonable to estimate the number of MODIS forest pixels $(500 \mathrm{~m})$ intersecting with the GLAS data to calculate the area represented. Taking the May-June data acquired in 2005 as an example, the number of GLAS data points from forested land is 1.67 million and 0.55 million before and after filtering, respectively. The number of forest pixels intersecting with GLAS data is 0.63 million and 0.30 million, respectively. Given that the number of global forest pixels is 129 million (based on the $500 \mathrm{~m} \mathrm{MCD12}$ product in 2006), the GLAS data represent $0.49 \%$ and $0.23 \%$ of the global forest before and after filtering, respectively. Therefore, data filtering does not lead to a dramatic decrease in forest representation.

\subsection{Peak distance retrieval}

Our new procedure combined the results of GLA14 and the wavelet method to obtain peak distance with a low risk of missing important peaks. Given that Gaussian fitting is effective under most conditions, most data used the first and last peaks extracted from the GLA14 products. Considering all the forests, approximately $13 \%$ of the GLAS data used the first or the last peak extracted with the wavelet method (Table 4). This percentage is an indicator of the usefulness of the wavelet method and it varied significantly with forest type. EBF showed the highest percentage (18.87\%), followed in descending order by DBF, ENF, MF, and DNF. The replacement of Gaussian peaks by wavelet peaks also results in increasing peak distance. As expected, the mean value of peak distance for EBF showed the most significant increase (26.90 m vs. $27.46 \mathrm{~m}$ ) in contrast to only a slight increase for DNF ( $16.37 \mathrm{~m}$ vs. $16.40 \mathrm{~m}$ ).

The global difference map between GLA14 peak distance and the new peak distance at spatial resolution of $0.5^{\circ} \times 0.5^{\circ}$ is shown in Fig. 3(a). South America exhibits the largest discrepancies, followed by Africa, Southeast Asia, and the West Coast and the eastern part of North America. The waveform reconstruction accuracy map $\left(R_{a}^{2}\right)$ is shown in Fig. 3(b). The regions with low $\mathrm{R}_{\mathrm{a}}^{2}$ are consistent with the regions showing large differences in peak distance. It can be inferred that forests in these regions have complicated waveforms, for which the GLA14 product often misses important peaks but the wavelet method mitigates this problem to some extent. We also found that the difference in peak distance is more significant in May-June than in FebruaryMarch, particularly in Northern Europe, Asia, and the eastern part of North America, which have a wide distribution of deciduous forests (not shown in this paper). Therefore, the peaks extracted by the wavelet method are more useful during the growing season, when the nonevergreen forest structure is more complicated, than during the dormant season.

\subsection{Seasonal variation of GLAS mean forest canopy height}

Table 5 shows a statistical comparison of GLAS mean forest canopy height from the three observation periods. The height statistics of EBF are nearly unaffected by season. For ENF, the mean value is not significantly influenced, but std. and CV (an indicator of data variation) increase clearly in February-March and in October-November. The height statistics of DNF, DBF, and MF change significantly with time, showing the largest mean value and lowest CV in May-June. Specifically, the mean value of mean forest canopy height for May-June is 2.16-2.77 m higher than that for February-March, and the CV value for May-June is $7.58 \%$ to $10.59 \%$ lower than that for February-March. The mean values of mean forest canopy height in October-November are moderate, indicating that October-November is likely to be a transition period. The CV values in October-November are notably large, which is unfavorable and is most likely caused by spatial variations in the time of leaf shedding. Deciduous forests at high latitudes have no leaves by October, but at middle latitudes, the time of leaf fall is postponed. The condition of deciduous and mixed forests is more spatially heterogeneous in October-November than in May-June. Thus, the height map comparison in the next paragraph includes only FebruaryMarch and May-June.

Fig. 4 shows the mean forest canopy height global map in May-June and in February-March, as well as their differences at $0.5^{\circ} \times 0.5^{\circ}$ spatial resolution. Although the two forest height maps demonstrate similar global distributions, the height difference map highlights the regions where seasonal variations can be clearly observed. The mean forest canopy height in May-June is clearly larger than that in February-March for Northeast Asia (mostly DNF), Central Europe (mostly ENF and MF), the eastern part of North America (mostly DBF), and the northern part of North America (mostly ENF). The height of the EBF in most tropical areas is higher in February-March than in May-June, although the magnitude of the difference is very small (Table 5). The seasonal impact on the height of the ENF is geographically dependent. In most parts of Europe and the northern part of North America, the ENF height is higher in May-June, but no such trend can be observed on the West Coast of North America. Different tree species (temperate rainforests on the West Coast of North America vs. boreal forests over high latitudes) and climatic features (little or no snow in winter vs. heavy snow in winter) could be the reason for this scenario.

The seasonal difference in the height of non-evergreen forests is caused mainly by the leaf status (leaf-on vs. leaf-off) because the canopy

Table 8

RMSE comparison of two BRF models (using climatic and RS data vs. using only climatic data) for short and tall trees in each geographic region.

\begin{tabular}{|c|c|c|c|c|c|c|c|}
\hline & Asia & North America & Africa & South America & Australasia & Siberia & Europe \\
\hline RMSE_BRF_Short (m) & 4.39 & 3.84 & 4.90 & 6.70 & 5.07 & 4.19 & 4.18 \\
\hline RMSE_BRF_Short_Climate (m) & 5.29 & 4.63 & 6.14 & 6.97 & 6.03 & 5.28 & 5.32 \\
\hline RMSE difference for short trees (\%) & 20.50 & 20.57 & 25.31 & 4.03 & 18.93 & 26.01 & 27.27 \\
\hline RMSE_BRF_Tall (m) & 6.66 & 5.11 & 5.40 & 7.56 & 6.93 & 4.07 & 4.42 \\
\hline RMSE_BRF_Tall_Climate (m) & 7.23 & 5.94 & 6.59 & 7.86 & 8.11 & 4.85 & 5.30 \\
\hline RMSE difference for tall trees (\%) & 8.56 & 16.24 & 22.04 & 3.97 & 17.03 & 19.16 & 19.91 \\
\hline
\end{tabular}


gap distribution largely determines the amount of scattered energy at a given height that returns to the sensor (Kimes et al., 2006). For the evergreen forest, showing relatively stable canopy conditions, seasonal height differences could be caused by variations in environmental or climatic factors. For example, on the West Coast of North America, high humidity in the atmosphere caused by summer fog moisture (Alaback, 1991) could attenuate the Lidar signal (1064 nm) and affect height retrieval results.

Based on the seasonal impact analysis, we used all of the seasonal GLAS data for the EBF and the GLAS data for May-June for the other forest

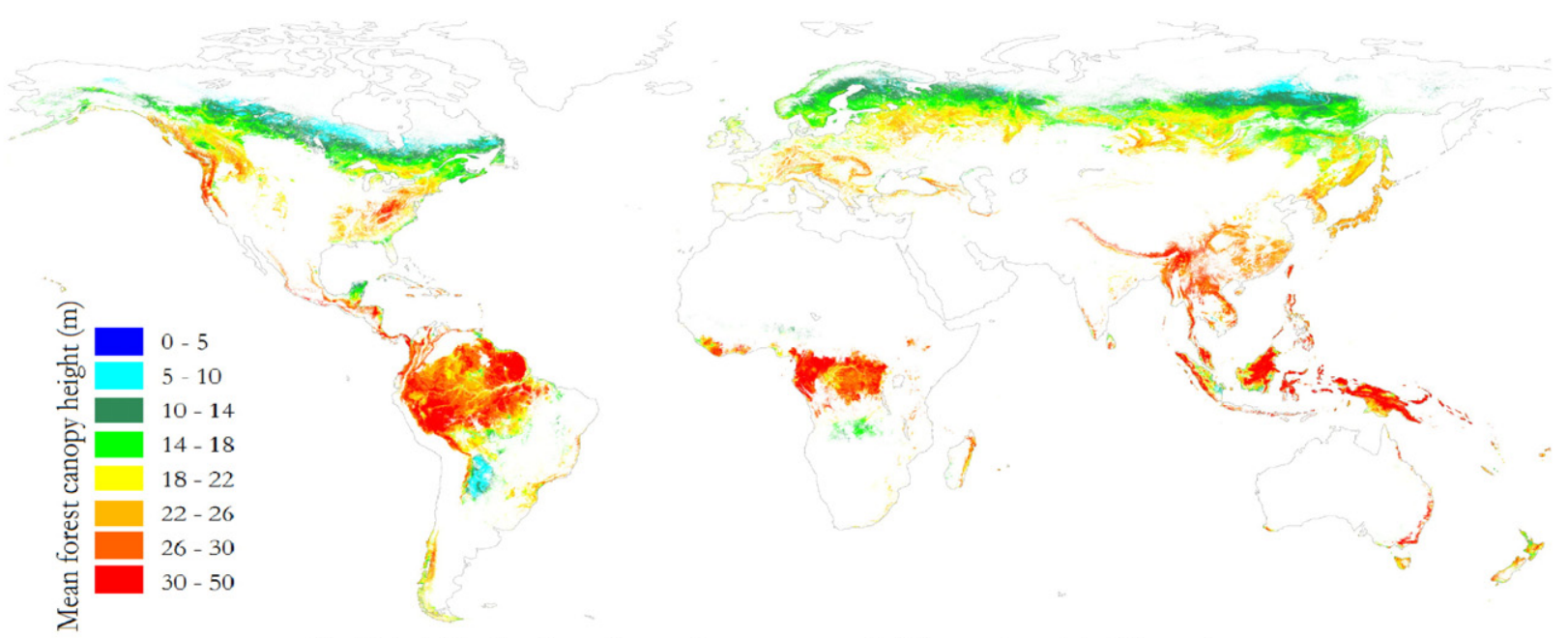

(a) Global distribution of mean forest canopy height produced in this study.

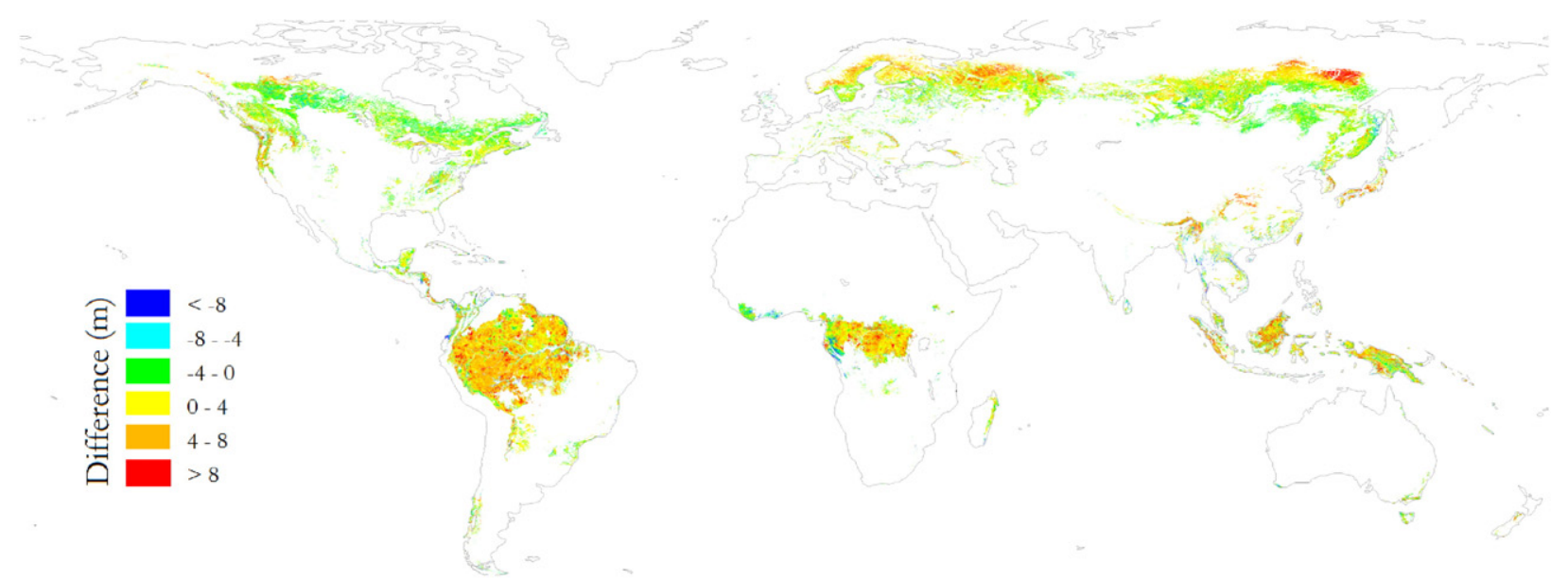

(b) Height difference map: RH100 of Simard et al. (2011) minus mean forest canopy height.

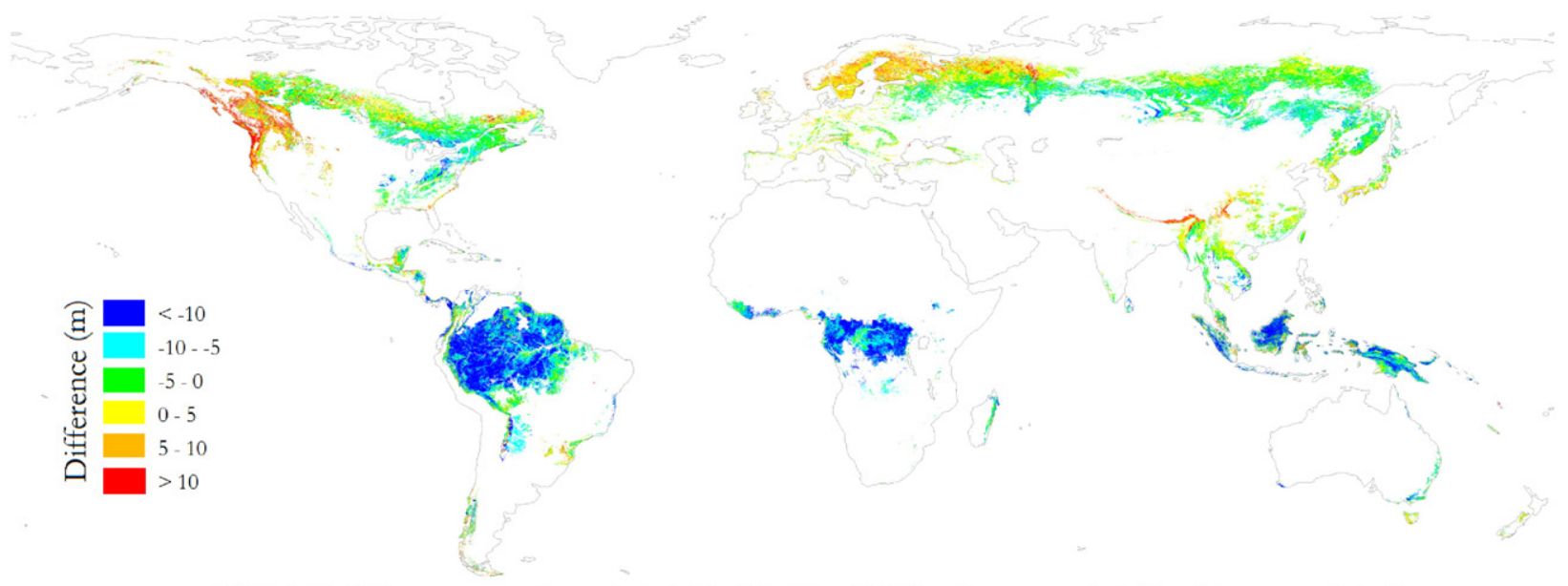

(c) Height difference map: Lorey's height of Lefsky (2010) minus mean height of the present study.

Fig. 5. Mean forest canopy height results of the present study and the difference map when compared with results of Simard et al. (2011) and Lefsky (2010). 
Table 9

Coefficients of determination $\left(\mathrm{R}^{2}\right)$ and RMSE obtained with pixel-by-pixel inter-comparison among the three forest height maps.

\begin{tabular}{lllc}
\hline & Simard vs. this study & Lefsky vs. this study & Simard vs. Lefsky \\
\hline $\mathrm{R}^{2}$ & 0.73 & 0.14 & 0.11 \\
RMSE $(\mathrm{m})$ & 4.49 & 8.92 & 11.19 \\
\hline
\end{tabular}

types. Because the seasonal impacts on ENF depend on geographic region, we used only the GLAS data acquired in May-June for convenience.

\subsection{Regional model training for mean forest canopy height estimation}

Table 6 shows the training accuracy of height prediction model in each geographic region and the training data statistics. The prediction accuracy varies among forest types and geographic regions. All of the coefficients of determination $\left(R^{2}\right)$ are larger than 0.8 , except for South America, which has an $R^{2}$ value of 0.59 . A low $R^{2}$ value could be caused by poor fitting or a narrow data range of forest canopy height. The RMSE ranges from 2.75 to $4.45 \mathrm{~m}$, with South America and Australasia showing relatively larger values.

The RF modeling performance is clearly inferior to the BRF performance, which can be observed clearly from the decreases in $\mathrm{R}^{2}$ (2.44-5.13\%) and the increases in RMSE (3.68-12.02\%). To highlight the accuracy difference in modeling the minority height class (i.e., short/tall trees), we calculated the modeling RMSE for short and tall trees, which is determined based on the 10th percentile and the 90th percentile of the height distribution in a geographic region, respectively (Table 6). It can be observed that the RMSE for the minority height classes of the BRF model is approximately $20 \%$ less than the RMSE of the RF model, indicating a more significant accuracy improvement for the minority classes than for all the samples (overall accuracy measure). An exception is South America, which shows the worst modeling performance as well as the slightest improvement from application of the BRF algorithm.

The BRF can maintain data variation better than the RF, which can be observed from the noticeably higher standard deviations (std) of the BRF model predictions. However, the reduction in the std. of predictions compared to the std. of the original GLAS is unavoidable for two reasons. First, the predicted values are averaged over a $500 \mathrm{~m}$ pixel, which is larger than the original $70 \mathrm{~m}$ GLAS footprint. A reduction in std. is reasonable in such a downscaling process. Second, when the relationship between mean forest canopy height and ancillary data is not straightforward, mean values are often taken as good estimations (Mclver and Friedl, 2002), leading to a smaller data range and a lower std. in the predicted values. Therefore, a large reduction in std. often indicates that the modeling work is difficult because of a weak correlation between mean forest canopy height and ancillary variables. For example, South America shows the lowest modeling accuracy, consistent with its largest reduction in std.

\subsection{Analysis of variable importance}

Table 7 lists the important variables identified in regional height prediction models. The variables in brackets are highly correlated with each other, which indicates that the information provided by these variables

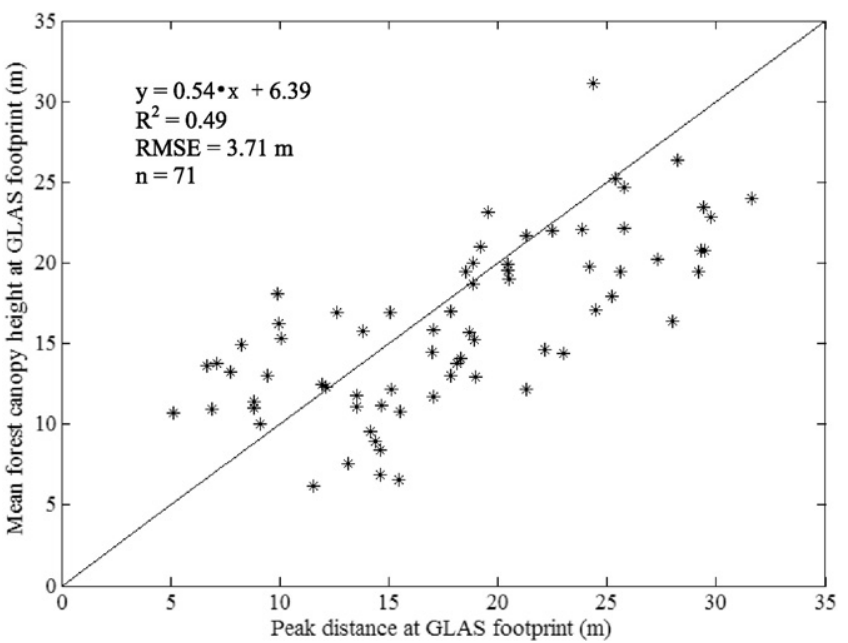

Fig. 6. Validation of GLAS height at the footprint level using field observation of the mean forest height.

is overlapped to some extent. Both the important variables and the correlations among the variables change with geographic region. The following analysis focuses on the variables that are identified as important with high frequency (i.e., by more regional models).

DEM is considered important across all seven regional models, but its influence is not conveyed consistently. In tropical areas (South America and Africa), DEM is highly correlated with mean air temperature, whereas in other regions, DEM is weakly correlated with other variables. It can be assumed that the influence of DEM on mean forest canopy height in tropical areas is mainly through the regulation of climatic features. In the other non-tropical regions, where latitude or other factors determine the main climatic regime, DEM has a more direct and independent impact on mean forest canopy height.

The mean_NIR is identified as an important variable in five regional models (Asia, Europe, South America, Africa, and Siberia). The mean_NIR is correlated with accumulated EVI (accum_EVI), which is usually considered an indicator of biomass, except in Siberia. In Siberia, mean_NIR is positively correlated with mean_red, which could be caused by the wide distribution of swampy taiga in this area. For dense forest with an underlying wet background, reflectance is low at both the red and the NIR bands. In Asia and Europe, accum_EVI is not considered important despite its high correlation with mean_NIR, indicating that accum_EVI cannot be a truly influential variable in the two regions.

Tree cover is identified as an important variable in four regional models (North America, Europe, Siberia, and Austrasia). In the former three regions, needleleaf forest is distributed widely. Tree cover increases notably with height for needleleaf forests because of their erectophile leaf arrangement and canopy shape. However, the relationship between tree cover and tree height is not straightforward for nonneedleleaf forests because tree cover saturates after the forest canopy height or biomass reaches a high value (Turner et al., 1999; Simard et al., 2011); thus, in Africa and South America, tree cover is not considered important in height modeling.

Mean_red is apparently important in four regional models (North America, Asia, Europe, and Siberia), but it actually only provides unique

Table 10

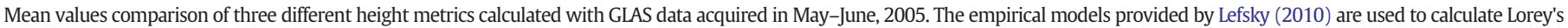
height. Given that terrain correction is used in the models, the filters associated with slope and bias test are not applied to the GLAS data when calculating Lorey's height.

\begin{tabular}{|c|c|c|c|}
\hline Forest type & Maximum height (m) & Mean height $(\mathrm{m})$ & Lorey's height (m) \\
\hline Evergreen needleleaf forest & 23.07 & 17.17 & 13.96 \\
\hline Evergreen broadleaf forest & 35.04 & 27.46 & 13.52 \\
\hline Deciduous needleleaf forest & 21.91 & 16.4 & 12.7 \\
\hline Deciduous broadleaf forest & 26.51 & 20.54 & 10.11 \\
\hline Mixed forest & 26.59 & 20.84 & 12.01 \\
\hline
\end{tabular}


Table 11

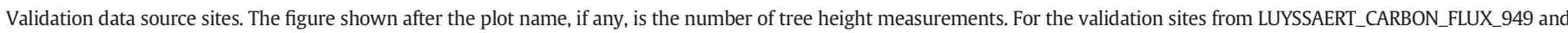
Fluxnet_buchmann_662 dataset, the stand age and the forest type are given if they are available in the original data files.

\begin{tabular}{|c|c|c|c|c|c|}
\hline Location or plot name & $\begin{array}{l}\text { Longitude } \\
\left({ }^{\circ}\right)\end{array}$ & $\begin{array}{l}\text { Latitude } \\
\left({ }^{\circ}\right)\end{array}$ & $\begin{array}{l}\text { Measurements } \\
(\mathrm{m})\end{array}$ & $\begin{array}{l}\text { Predictions } \\
(\mathrm{m})\end{array}$ & Dataset name, sources, and notes \\
\hline Harvard Forest (4) & -72.17 & 42.53 & 22.72 & 22.23 & \multirow{6}{*}{$\begin{array}{l}\text { NACP_FOREST_BIOPHYSICAL_1046 (Cook et al., 2011), only consider } \\
\text { dominant and co-dominant trees that are alive when calculating the } \\
\text { mean height. Observations are made in } 2008 \text {. }\end{array}$} \\
\hline Bartlett Experimental (608) & -71.17 & 44.04 & 17.11 & 17.91 & \\
\hline Howland Research (304) & -68.73 & 45.20 & 17.26 & 14.56 & \\
\hline Penobscott (593) & -68.65 & 44.87 & 18.29 & 16.67 & \\
\hline Sierra National Forest (319) & -118.83 & 36.72 & 29.02 & 28.20 & \\
\hline Hubbard Brook (184) & -71.45 & 43.56 & 24.40 & 22.61 & \\
\hline Fazenda Cauaxi (242) & -48.29 & -3.73 & 32.90 & 30.80 & $\begin{array}{l}\text { TG07_DBH_CAUAXI_1063 (Asner et al., 2012). Height is observed in } \\
2006 .\end{array}$ \\
\hline $\begin{array}{l}\text { Tapajos National Forest (height is given in } \\
\text { the comp pdf file of the dataset) }\end{array}$ & -54.96 & -2.86 & 30.00 & 32.84 & LC14_ABOVEGROUND_PROD_1196 (Nepstad \& Moutinho, 2013) \\
\hline NSA-ASP-AUX09 (887) & -97.34 & 56.00 & 6.90 & 9.32 & \multirow{7}{*}{$\begin{array}{l}\text { BOREAS_TE23MAPP_359 (Rich \& Fournier, 1999).Only consider the } \\
\text { plot growing old trees. Interpretation of the plot name: Old Black } \\
\text { Spruce (OBS); Old Jack Pine (OJP); Old Aspen (OA); Northern Study } \\
\text { Area (NSA); southern Study Area (SSA). }\end{array}$} \\
\hline NSA-OBS (1441) & -98.48 & 55.88 & 9.60 & 9.57 & \\
\hline NSA-OJP (641) & -98.62 & 55.93 & 10.70 & 9.50 & \\
\hline SSA-9OA (356) & -106.20 & 53.63 & 23.20 & 19.18 & \\
\hline SSA-MIX (1555) & -105.21 & 53.73 & 11.35 & 11.96 & \\
\hline SSA-OBS (664) & -105.12 & 53.99 & 11.30 & 17.36 & \\
\hline SSA-OJP (550) & -104.69 & 53.92 & 14.10 & 12.39 & \\
\hline Santarem 2004 35-45 (198) & -54.96 & -2.85 & 28.90 & 32.80 & \multirow{44}{*}{$\begin{array}{l}\text { LBA-ECO_TG07_FSM_836 (Keller et al., 2007) } \\
\text { LASELVA_BIOMASS_1215 (Goncalves et al., 2014) } \\
\text { LUYSSAERT_CARBON_FLUX_949 (Luyssaert et al., 2007, 2008). Only } \\
\text { the sites that are unmanaged and with mean tree height information } \\
\text { were considered. }\end{array}$} \\
\hline La Selva Biological Station, Costa Rica (1513) & -84.02 & 10.42 & 23.80 & 21.88 & \\
\hline Prince Albert SSA SOBS ( 115 years old, ENF) & -104.68 & 53.92 & 8.00 & 11.91 & \\
\hline Caxiuana ( 100 years old, EBF) & -51.45 & -1.72 & 35.00 & 31.78 & \\
\hline Canal Flats xeric ( 78 years old, ENF) & -115.25 & 50.10 & 20 & 20.76 & \\
\hline Ashu Kyoto ( 150 years old, DBF) & 135.75 & 35.33 & 14.00 & 26.62 & \\
\hline Yusuhara (294 years old, ENF) & 133.00 & 33.33 & 23.50 & 24.22 & \\
\hline Hubbard brook (110 years old, DBF) & -71.50 & 44.00 & 17.00 & 19.02 & \\
\hline Sylvania (350 years old, mixed forest) & -89.34 & 46.24 & 22.00 & 19.94 & \\
\hline Kuusamo ( 260 years old, ENF) & 29.33 & 66.37 & 16.00 & 13.54 & \\
\hline Yakutsk (125 years old, DNF) & 128.27 & 60.51 & 23.00 & 11.68 & \\
\hline San Carlos ( 230 years old, EBF) & -67.05 & 1.93 & 30.00 & 24.87 & \\
\hline Hainich (270 years old, DBF) & 10.45 & 51.08 & 35.00 & 23.44 & \\
\hline Cuieiras/C14 (observed in 1999) & -60.10 & -2.58 & 30.00 & 28.11 & \\
\hline Frazer old ( 245 years old, ENF) & -105.87 & 39.90 & 17.00 & 23.13 & \\
\hline Sapporo (observed in 2003, MF) & 141.38 & 42.98 & 20.00 & 24.84 & \\
\hline Yenisey Betula ( 50 years old, ENF) & 89.82 & 61.02 & 15.00 & 17.87 & \\
\hline Yenisey Abies (200 years old, ENF) & 89.76 & 61.02 & 22.00 & 19.22 & \\
\hline Yenisey Mixed ( 250 years old, MF) & 89.78 & 61.02 & 22.00 & 19.19 & \\
\hline Bonanza 5a (200 years old, ENF) & -148.25 & 64.75 & 8.00 & 20.68 & \\
\hline Aheden ( 180 years old, DBF) & 19.50 & 64.21 & 18.00 & 15.78 & \\
\hline Walker Branch ( 80 years old, DBF) & -84.28 & 35.96 & 25.00 & 27.66 & \\
\hline Niwot Ridge ( 100 years old, ENF) & -105.53 & 40.03 & 12.00 & 20.64 & \\
\hline Harvard (60 years old, DBF) & -72.17 & 42.53 & 24.00 & 22.23 & \\
\hline Howland ( 140 years old, ENF) & -68.74 & 45.20 & 20.00 & 15.10 & \\
\hline Prince Albert SSA SOAS (68 years old, DBF) & -106.2 & 53.63 & 20.00 & 19.18 & \\
\hline Thompson NSA NOBS ( 150 years old, ENF) & -98.47 & 55.90 & 9.00 & 8.70 & \\
\hline Xiaohu NF ( 150 years old, EBF) & 117.43 & 26.18 & 24.00 & 25.10 & \\
\hline Changbai Mountains (450 years old, MF) & 128.45 & 42.40 & 26.00 & 21.58 & \\
\hline Cascade Head 10 (185 years old, ENF) & -123.89 & 45.068 & 34.00 & 26.28 & \\
\hline Cascade Head 11 ( 168 years old, ENF) & -123.90 & 45.082 & 27.00 & 26.61 & \\
\hline Cascade Head 12 ( 178 years old, ENF) & -123.90 & 45.04 & 34.00 & 26.19 & \\
\hline New Zealand ( 300 years old, EBF) & 172.00 & -42.20 & 30.00 & 25.00 & \\
\hline Tennessee, US ( 50 years old, DBF) & -84.20 & 35.60 & 25.00 & 25.76 & \\
\hline Massachusetts, US ( $50-70$ years old, DBF) & -72.20 & 42.50 & 24.00 & 22.58 & \\
\hline Sask., Canada ( 70 years old, DBF) & -106.00 & 53.70 & 21.00 & 17.82 & \\
\hline Siberia ( 130 years old, DNF) & 128.00 & 60.50 & 20.00 & 12.97 & \\
\hline Germany (43 years old, ENF) & 11.50 & 50.10 & 18.00 & 23.19 & \\
\hline Sask., Canada (ENF) & -105.10 & 54.00 & 16.00 & 14.86 & \\
\hline Sask., Canada ( $75-90$ years old, ENF) & -105.00 & 53.90 & 13.50 & 15.84 & \\
\hline Siberia (215 years old, ENF) & 89.00 & 61.00 & 12.00 & 18.46 & \\
\hline Manitoba, Canada ( 120 years old, ENF) & -98.50 & 55.90 & 10.00 & 9.26 & \\
\hline Reserva Duke, Brazil (EBF) & -59.60 & -2.60 & 32.50 & 27.46 & \\
\hline Reserva Jaru, Brazil (EBF) & -61.60 & -10.00 & 30.00 & 30.70 & \\
\hline
\end{tabular}

information in North America and Asia. Mean_red is highly correlated with tree cover in Europe and with mean_NIR in Siberia.

ANIF is identified as important in two regions: Asia and North America. Although ANIF appears to be less important than the variables mentioned above (DEM, mean_NIR, tree cover), it provides information from an entirely new perspective for height modeling because ANIF is not correlated with any other variables. The small data range of ANIF (generally varying within 1.0-1.4 with a step size of 0.04 ) places it at a disadvantage in importance evaluation because variables with more categories are obviously preferred in building a regression tree of random forest (Strobl et al., 2007).

In addition to variable importance analysis with permutation methods, we also implemented the BRF with only seven climatic variables to quantify the contribution of RS variables. Table 8 shows that the removal of RS data led to a deterioration in modeling performance for almost all the regional models: $20 \%$ to $30 \%$ increase in RMSE and $10 \%$ to $20 \%$ decrease in $\mathrm{R}^{2}$. For South America, the removal of RS variables led to the most insignificant change in modeling accuracy $(5.6 \%$ 
increase in RMSE and 8.9\% decrease in $\mathrm{R}^{2}$ ), which is consistent with the permutation variable importance analysis in which only one RS variable (mean_NIR providing information on annual accumulated EVI) was identified as important in height modeling.

The modeling accuracy changes caused by removal of RS data vary not only across regions but also across height classes. The accuracy reduction for short trees is more significant than that for tall trees after RS data removal (Table 8). The most extreme contrast is in Asia where the RMSE for short and tall trees increased by $20.50 \%$ and $8.56 \%$, respectively. This phenomenon suggests that optical RS data could be less useful for dense and tall forests because of the saturation problem and low penetration capability.

\subsection{Mean forest canopy height mapping and analysis}

The global distribution of mean forest canopy height derived from the trained BRF model is shown in Fig. 5a. Tall trees can be found in tropical areas, the West Coast of North America, the Appalachian Mountains of North America, Southeast Asia, and the southeast coast of Australia. Short trees are found in the ENF and the DNF over high latitudes, the DBF in the Southern Hemisphere, and the EBF in the Yucatán Peninsula of Mexico.

Our results were compared with existing maps. Fig. 5b and c show two difference maps. Our results are lower than those of Simard et al. (2011) over high latitudes (i.e., Northeast Asia and Central Europe) and tropical areas (i.e., South America and Africa). The difference ranges from $-4 \mathrm{~m}$ to $4 \mathrm{~m}$ for other parts of the world. The results of Lefsky (2010) are lower in most areas, especially in tropical areas, and our height results are generally more than $10 \mathrm{~m}$ greater than Lefsky's results. However, our results for Northwest America and the Himalaya region, which have high mountains and complex terrains, are smaller than those of Lefsky. In Northeast Asia, where Simard et al.'s results are clearly greater than ours, Lefsky's results are similar to ours. The two difference maps share almost no common points, except that our results for Europe are lower than those of the other two results.

We layered the three maps in the ENVI software under geographic projection at a spatial resolution of $1 \mathrm{~km}$ to make a more quantitative intercomparison among the three height maps. Only five forest cover classes defined in the IGBP scheme were considered because Simard et al. (2011) used more inclusive forest categories from Hagolle et al. (2005). All of the pixels with three valid tree height values were included to calculate the $\mathrm{R}^{2}$ and the RMSE. Table 9 shows that our results are more consistent with those of Simard et al., whereas Lefsky's results are different from the other two. Compared with the results of Simard et al., our results are relatively closer to those of Lefsky, as indicated by the smaller RMSE and the larger $\mathrm{R}^{2}$ values.

Different height metrics are an important factor leading to differences among existing maps. Simard et al. mapped the maximum height defined as RH100. We mapped the mean height of dominant and codominant trees defined as peak distance. Lefsky mapped Lorey's height, which was calculated with slope correction empirical models. We calculated three height metrics from GLAS waveform data acquired in MayJune 2005 to understand the differences caused by the height metrics. Table 10 shows the mean values of the three height metrics for each forest type. Generally, the maximum height is greater than the mean height, and the mean height is greater than the Lorey's height. Canopy shape and upper canopy geometry influence the disparities among height metrics. The laser energy penetration is deeper for needleleaf forests, which usually have conical canopies (Lefsky et al., 2007), leading to a larger discrepancy between maximum and mean heights. The maximum height is also clearly greater than the mean height for the EBF, which often exhibits complicated upper canopy geometry, which is consistent with the difference map (Fig. 5b). The Lorey's height for the ENF and the DNF appears to be closer to the mean height, but for other forests (especially EBF), the Lorey's height is rather low (consistent with the difference map in Fig. 5c). Only 95 samples were used to build slope correction models for Lorey's height retrieval from broadleaf forest (Lefsky, 2010), which could introduce a large bias when this empirical model is applied to the worldwide GLAS data.

\subsection{Validation with field data}

Data from 71 plots with flat terrain $\left(<7^{\circ}\right)$ were collected to validate the mean forest canopy height at the GLAS footprint level. Fig. 6 shows that GLAS peak distance is moderately correlated with mean forest canopy height $\left(R^{2}=0.49\right.$, RMSE $\left.=3.71 \mathrm{~m}\right)$. Because of a slight tendency of overestimation for tall trees, the slope of the linear regression is 0.54 . The discrepancies between the GLAS-derived and the field-measured heights are related to large geo-location uncertainties of the field data (approximately $5 \mathrm{~m}$ to $10 \mathrm{~m}$ ) (Lee et al., 2011), measurement error, and subjective error caused by different observers and other factors. The inclusion of all of the data from different forest types could also be a factor. Despite the bias and moderate correlation, the error attributed to using peak distance as mean forest canopy height is acceptable ( $R M S E=3.71 \mathrm{~m}$ ).

After searching the forest height data on the DAAC websites, we found 59 sites that are available and suitable for validating the $500 \mathrm{~m}$ mean forest canopy height map. The detailed sites information is presented in Table 11. Some attributes in the database (if available) were used to increase the quality and representativeness of the validation samples. We only considered dominant and co-dominant trees that were alive and that had a height greater than $3 \mathrm{~m}$. The number of tree height measurements used to calculate the mean forest height is also provided. For the datasets Fluxnet_buchmann_662 (Buchmann \& Schulze, 2003) and LUYSSAERT_CARBON_FLUX_949 (Luyssaert et al., 2007,2008 ), only one representative figure is used because the original data do not have plot inventory information. To alleviate the time mismatch between observation and estimation, we only considered the unmanaged sites with a stand age of more than 50 years and a mean forest canopy height greater than $3 \mathrm{~m}$. The reason why we only considered unmanaged sites is that anthropogenic activities at managed sites could lead to abrupt height changes over a short period of time.

Fig. 7 shows a scatter plot of the measured and the predicted mean forest canopy height results. Our results are generally consistent with the validation dataset $\left(\mathrm{R}^{2}=0.63\right.$, RMSE $\left.=4.68 \mathrm{~m}\right)$. The RMSE for Simard et al. (2011) is $5.25 \mathrm{~m}$, which is larger than ours. The RMSE for Lefsky (2010) is $8.90 \mathrm{~m}$, significantly larger than the other two results. The difference in height metric complicates the validation error comparison. The validation results would be more valid if maximum height or Lorey's height of the sites were used. However, it remains convincing that the mean forest canopy height mapping in this study achieved a good performance. Lefsky et al. (2007) argued that the likely upper limit of precision for mean height estimates from the GLAS waveforms is $5 \mathrm{~m}$. Considering this argument, we achieved a successful mapping of the global distribution of mean forest canopy height. However, at several sites, the height difference between observation and estimation is more than $10 \mathrm{~m}$, which demands further investigation to identify the reason for the difference (modeling error, unreliable sites, or other reasons). Moreover, the validation results could be biased because the distribution of validation sites is not uniform; most are from the Northern and Western Hemispheres. Additional validation work should be conducted in the future to obtain more comprehensive conclusions.

\section{Discussion}

This study contributes to the existing research efforts of estimating forest height globally by providing a distribution of mean forest canopy height at $500 \mathrm{~m}$ resolution. There are important differences in terms of filtering criteria, canopy height metric, ancillary variables, and modeling strategy compared to other studies. 


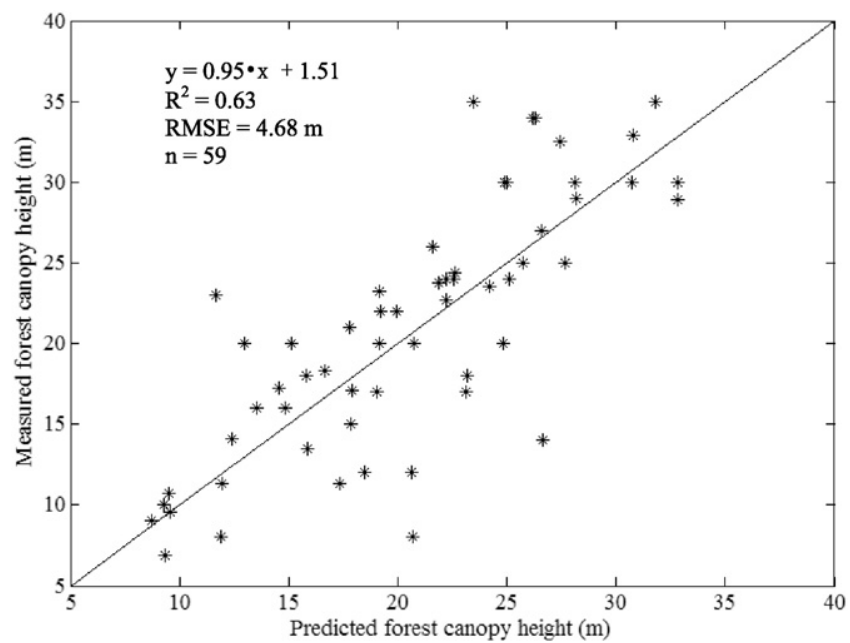

Fig. 7. Validation of height modeling results with $500 \mathrm{~m}$ pixels using the mean forest height of validation sites found at the DAAC website.

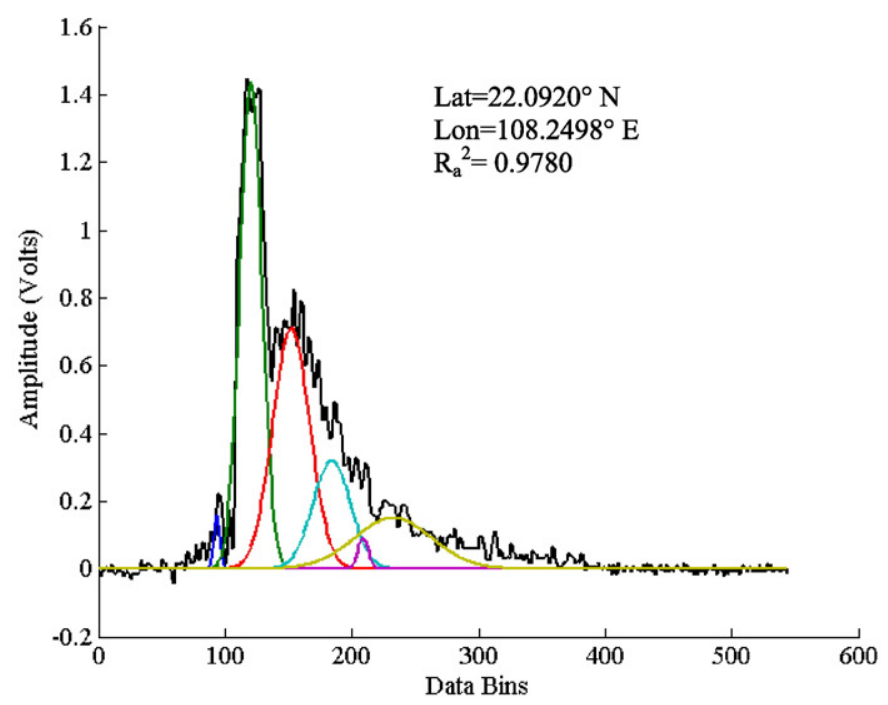

(a)

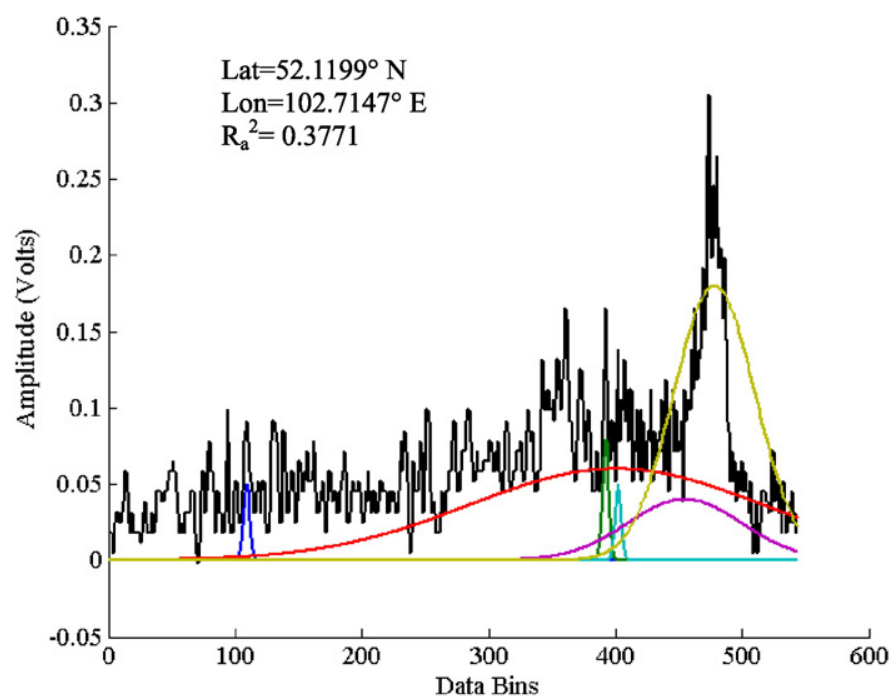

(c)

\subsection{Use of reconstruction accuracy $\left(R_{a}^{2}\right)$ as a filter}

Only the GLAS data for which $R_{a}^{2}$ exceeded a threshold ( 0.8 in this study) were selected, and to our knowledge this is the first attempt to examine reconstruction accuracy in this respect. Although the GLAS data failing to meet this criterion account for only a small percentage (usually less than $4 \%$ ), the effect is not negligible for height retrieval and height modeling.

First, a low $\mathrm{R}_{\mathrm{a}}^{2}$ indicates that the GLAS waveforms are noisy or have untypical shapes that the Gaussian method cannot decompose successfully. Fig. 8 provides some examples of waveforms, from which it can be observed that the Gaussian component, especially the Gaussian component 1 representing the ground return (Fig. $8 \mathrm{~b}, \mathrm{c}$ ), is very uncertain and easily leads to overestimation of peak distance. Because we determined mean forest canopy height directly from waveform peaks, it was necessary to remove GLAS data with unreliable peaks.

Second, mean forest canopy height modeling accuracy would decrease if the GLAS data with a low $R_{a}^{2}$ were included. For Asia and Australasia, the RMSE increment could be as large as $10 \%$, whereas for Siberia and Europe, the RMSE increment would be minimal because of a very low percentage of GLAS data with a low $R_{\mathrm{a}}^{2}$ (Table 12).

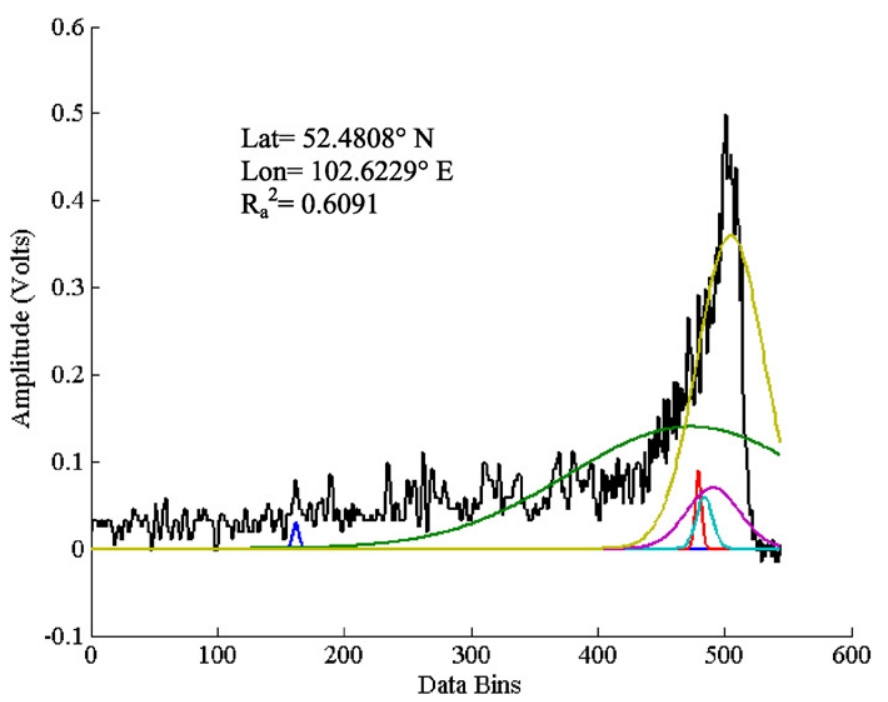

(b)

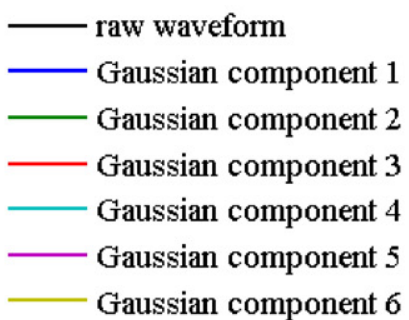

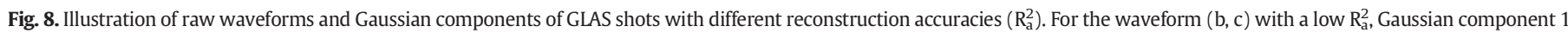
representing the ground return is very uncertain and easily leads to an over-estimation of peak distance. 
Table 12

The height modeling RMSE increment if $\mathrm{R}_{\mathrm{a}}^{2}>0.8$ is not included as a filter.

\begin{tabular}{|c|c|c|c|c|c|c|c|}
\hline & Asia & North America & Africa & South America & Australasia & Siberia & Europe \\
\hline $\begin{array}{l}\text { RMSE }(\mathrm{m}) \\
\left(\mathrm{R}_{\mathrm{a}}^{2}>0.8 \text { included as a filter }\right)\end{array}$ & 3.66 & 3.22 & 3.30 & 4.45 & 4.09 & 2.75 & 2.85 \\
\hline $\begin{array}{l}\text { RMSE }(m) \\
\left(R_{a}^{2}>0.8 \text { is not included as a filter }\right)\end{array}$ & 4.06 & 3.35 & 3.46 & 4.65 & 4.58 & 2.76 & 2.88 \\
\hline RMSE increment (\%) & 10.93 & 4.04 & 4.85 & 4.49 & 11.98 & 0.36 & 1.05 \\
\hline
\end{tabular}

Third, the GLAS data with low $\mathrm{R}_{\mathrm{a}}^{2}$ values are mostly from steep regions, so the slope filter that is applied first would remove a large proportion of the GLAS data with low $\mathrm{R}_{\mathrm{a}}^{2}$. For the remaining GLAS data from flat regions, the low $R_{a}^{2}$ values are questionable. Table 13 is an example comparing the height statistics under 6 conditions (3 slope groups by $2 R_{a}^{2}$ groups). The mean values of GLAS mean forest canopy height should increase with slope due to the broadening effect, which can be observed from the GLAS data with high $\mathrm{R}_{\mathrm{a}}^{2}$ values. However, for the GLAS data with low $\mathrm{R}_{\mathrm{a}}^{2}$, height values from flat regions are the largest and most unstable, which is abnormal and causes doubt about the utility of these data. Therefore, $\mathrm{R}_{\mathrm{a}}^{2}$ is not an excessive filter once the GLAS data are confined to flat regions.

\subsection{Peak retrieval}

We combined Gaussian fitting and the wavelet method to calculate peak distance based on the recognition that there would be a high risk of missing peaks if relying only on GLA14 products. The first (or last) peaks identified by the wavelet method were used when they had stronger amplitudes and occurred before the first (or after the last) Gaussian component peaks. The results showed that for most areas over high latitudes, the GLA14 product is better than the wavelet method. However, the wavelet method peaks were more frequently used in tropical areas and on the West Coast of North America, which suggests that the wavelet method is more effective for dealing with waveforms associated with complicated forest structure.

Despite the good performance achieved, this new combination procedure still requires improvement. For example, the peak amplitude or peak area should be sufficiently large to be identified as an important peak. Such necessity is strengthened further by the tendency of overestimation for tall trees observed in validation work at the GLAS footprint level. When the peak is not sufficiently strong to represent the main canopy return, the mean forest canopy height is easily exaggerated. Perhaps the first canopy return with an amplitude exceeding a threshold is a more realistic measure of mean forest canopy height.

\subsection{Seasonal variation}

In the results analysis (Section 3.3), seasonal variation in mean forest canopy height was demonstrated. We admit that these GLAS shots were not in exactly the same locations, but they were very close in either the along-track direction or the cross-track direction because ICESat used precision pointing to repeat within $35 \mathrm{~m}$ of the reference track
(Brenner et al., 2004; Urban et al., 2008). Many studies have applied repeat track analysis to calculate elevation change, confirming that temporal change analysis is feasible for GLAS data (Shuman et al., 2006; Moholdt et al., 2010). Moreover, we focused on the seasonal change of the statistics, namely the means and the standard deviations, calculated based on a large amount of GLAS data. It is unlikely that slight changes in the locations of the GLAS shots could influence the statistics greatly. Forest status and climatic/environmental factors should contribute more to such seasonal variation.

Another issue is that different waveform indices are affected by season at different levels. We found that the maximum heights for the DBF, the DNF, and the MF are less affected by the season than the mean tree heights, but the difference contrast for the EBF and the ENF is insignificant (Table 14). The DNF shows the most remarkable difference contrast: average maximum height and average mean height are $21.91 \mathrm{~m}$ and $16.40 \mathrm{~m}$ in May-June vs. $21.37 \mathrm{~m}$ and $14.48 \mathrm{~m}$ in FebruaryMarch, respectively. The mean forest canopy height is more related to the energy distribution of the waveforms. Given that leaves are the main medium that interacts with laser energy, leaf status (leaf-on vs. leaf-off) has a direct impact on mean forest canopy height retrieval. The maximum tree height depends on the beginning of the signal and is affected to a lesser extent by the leaf condition.

\subsection{Application of the ANIF}

The usefulness of the MODIS BRDF product for mapping forest canopy height was explored for the first time in this study. The results showed that the ANIF is effective for mean forest canopy height modeling in Asia and North America. Initial attempts included other shape indicators (e.g., NDAX, SSI, and ANIX), but no improvements were obtained. Thus, these indicators were removed from the list of ancillary variables.

Admittedly, ANIF is not as important as expected, which can be attributed to its small data range, insensitivity to height variation of some forest types, and most likely a terrain effect on the ANIF (Chen et al., 2005). Fig. 9 depicts the mean heights for different ANIF values that are within the ANIF range of each forest type. It can be observed that the ANIF of the ENF has the largest dynamic range and increases clearly with height. Although the DNF and the DBF show a positive relationship between ANIF and height, the ANIF data range is quite small. For the EBF and the MF, ANIF changes very mildly or slightly with height. Therefore, ANIF is most notably responsive for the height of the ENF. The ENF has an erectophile canopy that is usually viewed at a

Table 13

Height statistic comparison for GLAS data (acquired over Asian region during May-June, 2005) under 6 different conditions.

\begin{tabular}{|c|c|c|c|c|}
\hline $\begin{array}{l}\text { Reconstruction } \\
\text { accuracy }\end{array}$ & Slope & $\begin{array}{l}\text { Number of GLAS } \\
\text { shots }\end{array}$ & $\begin{array}{l}\text { Mean values of GLAS mean forest canopy height } \\
(\mathrm{m})\end{array}$ & $\begin{array}{l}\text { Std values of GLAS mean forest canopy height } \\
(\mathrm{m})\end{array}$ \\
\hline $\mathrm{R}_{\mathrm{a}}^{2} \leq 0.8$ & $\begin{array}{l}\text { Slope } \leq 7^{\circ} \\
\text { slope }>7^{\circ} \text { and slope } \leq 15^{\circ} \\
\text { slope }>15^{\circ} \text { and slope } \leq \\
30^{\circ}\end{array}$ & $\begin{array}{l}1018 \\
2709 \\
4215\end{array}$ & $\begin{array}{l}58.1463 \\
50.3436 \\
49.9721\end{array}$ & $\begin{array}{l}32.0616 \\
24.0478 \\
18.4337\end{array}$ \\
\hline $\mathrm{R}_{\mathrm{a}}^{2}>0.8$ & $\begin{array}{l}\text { Slope } \leq 7^{\circ} \\
\text { slope }>7^{\circ} \text { and slope } \leq 15^{\circ} \\
\text { slope }>15^{\circ} \text { and slope } \leq \\
30^{\circ}\end{array}$ & $\begin{array}{l}30,104 \\
36,636 \\
16,985\end{array}$ & $\begin{array}{l}18.7830 \\
23.2318 \\
28.1935\end{array}$ & $\begin{array}{l}9.1178 \\
9.1390 \\
9.5998\end{array}$ \\
\hline
\end{tabular}


Table 14

Comparison of the mean values of the GLAS maximum height and GLAS mean height between May-June and February-March for each forest type.

\begin{tabular}{|c|c|c|c|c|c|c|}
\hline & \multicolumn{3}{|c|}{ Maximum height (m) } & \multicolumn{3}{|c|}{ Mean height (m) } \\
\hline & May-June & February-March & Difference & May-June & February-March & Difference \\
\hline Evergreen needleleaf forest & 23.07 & 24.16 & -1.09 & 17.17 & 17.33 & -0.16 \\
\hline Evergreen broadleaf forest & 35.04 & 35.59 & -0.55 & 27.46 & 27.55 & -0.08 \\
\hline Deciduous needleleaf forest & 21.91 & 21.37 & 0.54 & 16.40 & 14.48 & 1.92 \\
\hline Deciduous broadleaf forest & 26.51 & 23.67 & 2.83 & 20.54 & 17.46 & 3.08 \\
\hline Mixed forest & 26.59 & 25.08 & 1.51 & 20.84 & 18.11 & 2.74 \\
\hline
\end{tabular}

high solar zenith angle. Under such conditions, the reflectance shows a minimum value in the forward scatter direction and a maximum value in the backscatter direction (Sandmeier et al., 1998). Tall and dense forests exhibit more back-shadows, indicating a strong anisotropy and a large ANIF value. However, many studies have demonstrated that single-band multi-angle data are insufficient in extracting canopy structure parameters. The spectral invariants that are indicative of structural information must be derived from multiple bands (Heiskanen, 2006; Kimes et al., 2006; Schull et al., 2007). In the future, it will be worthwhile to explore whether other BRDF indices (such as escape probability or shape indicators based on MISR data) are advantageous to global forest height modeling.

\subsection{Selection of the modeling algorithm (BRF)}

Compared to the original RF, the BRF algorithm applied in this study achieved better performance, which can be observed from the lower modeling error (RMSE) and the higher std. of predictions (data variations). The superiority of the BRF lies in the technique of discretization and sampling. Notably, great care should be taken with the discretization scheme. An excessive class number increases the total RMSE significantly, whereas fewer classes decrease the dynamic range and the variation of prediction to be similar to the original RF. The appropriate number of classes ranges from 6 to 10, and we chose 7 in this study. The idea of discretization is important for global scale modeling. For example, Saatchi et al. (2011) found that the MaxEnt model, which also requires a discretization step, outperformed two other methods (i.e., Random Forest and Maximum-likelihood) in mapping forest carbon stocks in tropical regions across three continents. We may compare MaxEnt and BRF in a future study of height modeling.

\subsection{Comparison with potential maximum tree height in the USA}

In addition to the machine learning methods applied in most height modeling studies, other methods can also be used to produce regional forest canopy height. For example, Shi et al. (2013) and Choi et al. (2013) used the Allometric Scaling and Resource Limitations (ASRL) model, which predicts potential maximum tree height using a combination of allometric scaling laws and energy budgets constrained by local resource limitations. Shi et al. (2013) mapped tree height over forested land in the continental United States at a spatial resolution of $1 \mathrm{~km}$ using the optimized ASRL model. We compared our tree height map with that of Shi et al. and found that their results are generally larger than ours and that correlation at the pixel level is low. The most important reason for this condition is that they mapped potential maximum tree height, whereas we mapped mean forest canopy height. Another reason is that the ASRL model is optimized for each climate zone, which could be too coarse for height estimation at the pixel level. However, the ASRL model is effective at depicting climatic effects on tree growth, so the potential maximum tree height of the ASRL model might be used as an ancillary variable in height modeling in the future.

\subsection{Prospects of forest canopy height mapping}

Many forested areas are heterogeneous because of anthropogenic and natural disturbances. Some researchers have mapped global forest change (Hansen et al., 2013) and global tree cover (Sexton et al., 2013) with Landsat data at $30 \mathrm{~m}$ spatial resolution. Tree cover is closely related to tree height, so global tree height could also be mapped at $30 \mathrm{~m}$ in the future, which would provide additional valuable information for global carbon cycle study. Moreover, the Global Ecosystem

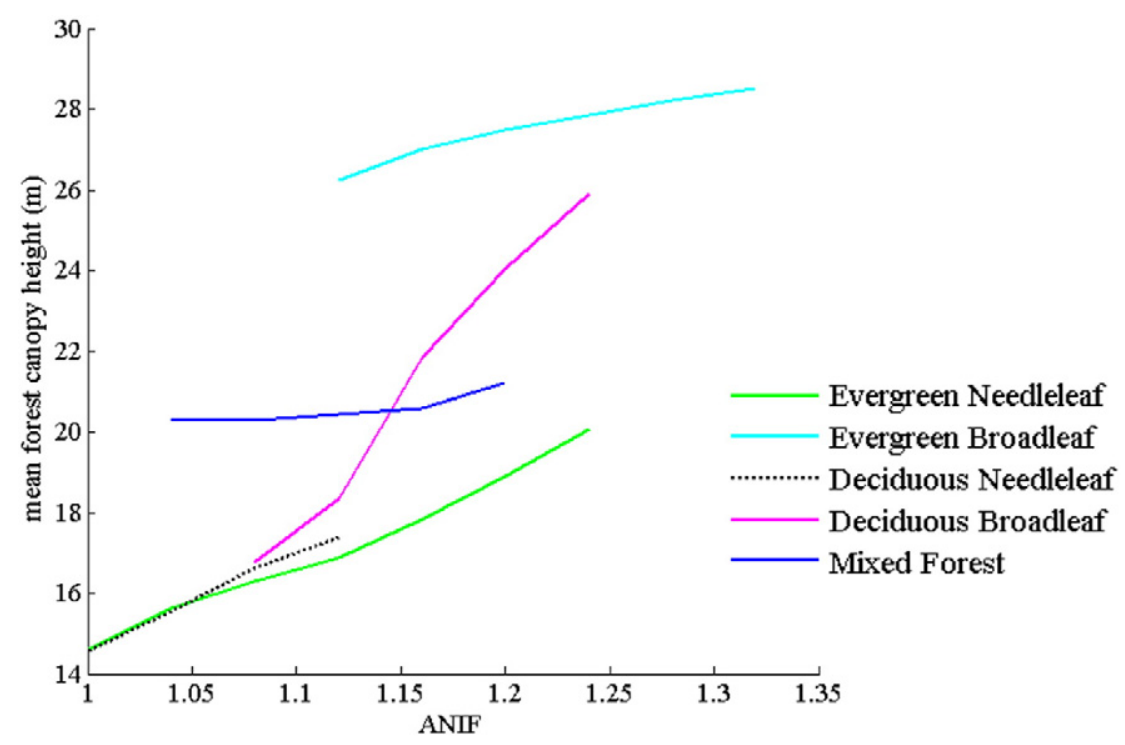

Fig. 9. Change in the mean forest canopy height with increasing ANIF value for different forest types. The data range of the ANIF value is the [mean - std., mean + std] for each forest type. 
Dynamics Investigation Lidar (GEDI) mission (http://science.nasa.gov/ missions/gedi/) will provide high-resolution observations of forest vertical structure. Combing GEDI and satellite data at fine spatial resolution $(<100 \mathrm{~m})$ will be a trend in mapping forest vertical structure, carbon balance and change, and habitat quality, among others.

\section{Conclusions}

Forest canopy height has a direct relationship with aboveground carbon storage, and the exchange of carbon between forests and the atmosphere is a vital component of the global carbon cycle (Lefsky et al., 2005). The study of global forest height mapping using satellite laser altimetry data and ancillary data (i.e., spectral and climatic) has received increasing attention in recent years. Although useful results have been obtained, some aspects still deserve further exploration. This study presented a global map of mean forest canopy height at a $500 \mathrm{~m}$ spatial resolution, and focused on the determination of waveform peaks, selection of ancillary variables, acquired time of GLAS data, and the modeling algorithm. Our main findings are as follows: (1) The wavelet method is effective for dealing with complicated waveforms with low reconstruction accuracy. (2) The ANIF is useful for height modeling in Asian and North American regions, and it shows a good correspondence with the height of evergreen needleleaf forests. (3) The mean forest canopy height difference between growing and dormant seasons is notable for deciduous and mixed forests. (4) The BRF algorithm can achieve higher modeling accuracy and more effectively preserve data variation compared to the commonly used RF algorithm.

The geographic distribution of our mean forest canopy height results at the global level appears reasonable. An inter-comparison among the three global height maps indicates that our results are more similar to those of Simard et al. (2011). However, our results show a better correlation with those of Lefsky (2010) than the correlation between those of Simard et al. (2011) and Lefsky (2010). The differences among the three results could be caused by many factors, such as the forest height metric, the acquired time of the GLAS data, ancillary variables, the modeling algorithm, the land cover product, the GLAS data processing algorithm, and the filtering criteria. Although we believe that the forest height metric contributes most to the differences, the regions that show larger differences merit intensive future study. Using the forest height data (FLUXNET sites and inventory plots with plenty of measurements) freely available on DAAC, we validated our results and obtained favorable accuracy $\left(\mathrm{R}^{2}=0.63\right.$, RMSE $\left.=4.68 \mathrm{~m}, \mathrm{n}=59\right)$.

We acknowledge that we excluded GLAS data from areas of moderate or high relief and that this is a limitation of this study. We also acknowledge that limiting GLAS footprints to those with a high $\mathrm{R}_{\mathrm{a}}^{2}$ value may have reduced the number of GLAS footprints returned from high biomass and complex canopies. However, we feel that these filters were necessary given the limitations of GLAS data (i.e., height estimates are more accurate in fairly homogeneous, open canopies over flat terrain). Our forest height map is therefore expected to be more accurate in flat areas with relatively simple forests. Further research should be conducted to validate our estimates in other, more complicated systems.

\section{Acknowledgements}

This research was supported by the National Basic Research Program of China (973 Program) for Global Change (2010CB950701) and the National Natural Science Foundation of China (41371400, 41301461). We thank the GLAS science team for providing the excellent and accessible data products that made this paper possible. We thank anonymous reviewers whose constructive comments led to a better presentation of our research methods and results. We also thank Professor S. Munro from University of Toronto and Dr. D. Wang from University of Maryland for providing help of language polishing.

\section{References}

Alaback, P. B. (1991). Comparative ecology of temperate rainforests of the Americas along analogous climatic gradients. Revista Chilena de Historia Natural, 64, 339-412.

Anderson, J., Martin, M. E., Smith, M. L., Dubayah, R. O., Hofton, M. A., Hyde, P., ... Knox, R. G. (2006). The use of waveformLiDAR to measure northern temperate mixed conifer and deciduous forest structure in New Hampshire. Remote Sensing of Environment, 105, 248-261.

Asner, G., Palace, M., Keller, M., Pereira, M., Silva, J., \& Zweede, J. (2012). LBA-ECO TG-07 tree geometry in an undisturbed forest in Cauaxi, Para, Brazil. Data set. Available on-line [http://daac.ornl.gov] from Oak Ridge, Tennessee, U.S.A.: Oak Ridge National Laboratory Distributed Active Archive Center. http://dx.doi.org/10.3334/ORNLDAAC/1063.

Baccini, A., Goetz, S. J., Walker, W. S., Laporte, N. T., Sun, M., Sulla-Menashe, D., .. Houghton, R. A. (2012). Estimated carbon dioxide emissions from tropical deforestation improved by carbon-density maps. Nature Climate Change, 2, 182-185.

Baghdadi, N., le Maire, G., Fayad, I., Bailly, J. S, Nouvellon, Y. Lemos, C. \& Hakamada, R. (2013). Testing different methods of forest height and aboveground biomass estimations from ICESat/GLAS data in Eucalyptus plantations in Brazil. IEEE Journal of Selected Topics in Applied Earth Observations and Remote Sensing. http://dx.doi.org/10.1109/ JSTARS.2013.2261978.

Boudreau, J., Nelson, R. F., Margolis, H. A., Beaudoin, A., Guindon, L., \& Kimes, D. S. (2008). Regional aboveground forest biomass using airborne and spaceborne LiDAR in Québec. Remote Sensing of Environment, 112, 3876-3890.

Breiman, L. (2001). Random forest. Machine Learning, 45, 5-32.

Brenner, A. C., Zwally, H. J., Shuman, C., \& Yi, D. H. (2004). ICESat capability for elevation change studies with sets of 33-day and 8-day cycles, January, 2004. (nsidc.org/data/ docs/daac/glas_altimetry/brenner_etal_2004_1.pdf, access on 2015-7-13).

Buchmann, N., \& Schulze, E. D. (2003). Net carbon dioxide and water fluxes of global terrestrial ecosystems, 1969-1998. Data set. Available on-line [http://www.daac.ornl.gov] from Oak Ridge, Tennessee, U.S.A.: Oak Ridge National Laboratory Distributed Active Archive Center. http://dx.doi.org/10.3334/ORNLDAAC/662.

Chen, C., Liaw, A., \& Breiman, L. (2004). Using random forest to learn imbalanced data. Berkeley: University of California (http://oz.berkeley.edu/users/chenchao/666. pdf).

Chen, J. M., Menges, C. H., \& Leblanc, S. G. (2005). Global mapping of foliage clumping index using multi-angular satellite data. Remote Sensing of Environment, 97, 447-457.

Chen, Q. (2010). Retrieving vegetation height of forests and woodlands over mountainous areas in the Pacific coast region using satellite laser altimetry. Remote Sensing of Environment, 114, 1610-1627.

Choi, S. H., Ni, X. L., Shi, Y. L., Ganguly, S., Zhang, G., Duong, H. V., ... Myneni, R. B. (2013). Allometric scaling and resource limitations model of tree heights: Part 2. Site based testing of the model. Remote Sensing, 5, 202-223. http://dx.doi.org/10.3390/rs5010202.

Chopping, M. (2011). CANAPI: Canopy analysis with panchromatic imagery. Remote Sensing Letters, 2(1), 21-29. http://dx.doi.org/10.1080/01431161.2010.486805.

Chopping, M., Moisen, G. G., Su, L. H., Laliberte, A., Rango, A., Martonchik, J. V., \& Peters, D. P. C. (2008). Large area mapping of southwestern forest crown cover, canopy height, and biomass using the NASA multiangle imaging spectro-radiometer. Remote Sensing of Environment, 112, 2051-2063.

Cook, B., Dubayah, R., Hall, F. G., Nelson, R., Ranson, J., Strahler, A. H., ... Griffith, P. (2011). NACP New England and Sierra National Forests Biophysical Measurements: 2008-2010. (Data set. Available on-line [http://daac.ornl.gov] from Oak Ridge, Tennessee, U.S.A: Oak Ridge National Laboratory Distributed Active Archive Center. http://dx.doi.org/ 10.3334/ORNLDAAC/1046.

Dong, J., Kaufmann, R. K., Myneni, R. B., Tucker, C. J., Kauppi, P. E., Liski, J., ... Hughes, M. K. (2003). Remote sensing estimates of boreal and temperate forest woody biomass: Carbon pools, sources, and sinks. Remote Sensing of Environment, 84, 393-410.

Duncanson, L. I., Niemann, K. O., \& Wulder, M. A. (2010). Estimating forest canopy height and terrain relief from GLAS waveform metrics. Remote Sensing of Environment, 114, 138-154.

Duong, V. H., Lindenbergh, R., Pfeifer, N., \& Vosselman, G. (2008). Single and two epoch analysis of ICESat full waveform data over forested areas. International Journal of Remote Sensing, 29, 1453-1473.

Duong, V. H., Lindenbergh, R., Pfeifer, N., \& Vosselman, G. (2009). ICESat full-waveform altimetry compared to airborne laser scanning altimetry over The Netherlands. IEEE Transactions on Geoscience and Remote Sensing, 47, 3365-3378.

Fricker, H. A., \& Padman, L. (2006). Ice shelf grounding zone structure from ICESat laser altimetry. Geophysical Research Letters, 33, L15502. http://dx.doi.org/10.1029/ 2006 GL026907.

Gao, F., Schaaf, C. B., Strahler, A. H., Jin, Y., \& Li, X. (2003). Detecting vegetation structure using a kernel-based BRDF model. Remote Sensing of Environment, 86, 198-205.

Genuer, R., Poggi, J. M., \& Tuleau-Malot, C. (2010). Variable selection using random forests. Pattern Recognition Letters, 31, 2225-2236.

Goncalves, F. G., Treuhaft, R. N., Santos, J. R., \& Graca, P. M. L. A. (2014). Forest Structure and Biomass Data, La Selva, Costa Rica, 2006. Data set. Available on-line (http://daac.ornl. gov) from Oak Ridge, Tennessee, USA.: ORNL DAAC. http://dx.doi.org/10.3334/ ORNLDAAC/1215.

Hagolle, O., Lobo, A., Maisongrande, P., Cabot, F., Duchemin, B., \& De Pereyra, A. (2005). Quality assessment and improvement of temporally composited products of remotely sensed imagery by combination of VEGETATION 1 and 2 images. Remote Sensing of Environment, 94, 172-186. http://dx.doi.org/10.1016/j.rse.2004.09.008.

Hansen, M. C., DeFries, R. S., Townshend, J. R. G., Carroll, M., Dimiceli, C. \& Sohlberg R. A. (2003). Global percent tree cover at a spatial resolution of 500 meters: First results of the MODIS vegetation continuous fields algorithm. Earth Interactions, $7(10), 1-15$ 
Hansen, M. C., DeFries, R. S., Townshend, J. R. G., Marufu, L., \& Sohlberg, R. (2002). Development of a MODIS tree cover validation data set for Western Province, Zambia. Remote Sensing of Environment, 83(1-2), 320-335.

Hansen, M. C., Potapov, P. V., Moore, R., Hancher, M., Turubanova, S. A., Tyukavina, A., .. Townshend, J. R. G. (2013). High-resolution global maps of 21st-century forest cover change. Science, 342, 850-853.

Harding, D. J., \& Carabajal, C. C. (2005). ICESat waveform measurements of within-footprint topographic relief and vegetation vertical structure. Geophysical Research Letters, 32, L21S10. http://dx.doi.org/10.1029/2005GL023471.

Heiskanen, J. (2006). Tree cover and height estimation in the Fennoscandian tundra-taiga transition zone using multiangular MISR data. Remote Sensing of Environment, 103, 97-114.

Helmer, E. H., \& Lefsky, M. A. (2006). Forest canopy heights in Amazon River basin forests as estimated with the Geoscience Laser Altimeter System (GLAS). USDA Forest Service Proceedings RMRS-P-42CD (pp. 802-808).

Hijmans, R. J., Cameron, S. E., Parra, J. L., Jones, P. G., \& Jarvis, A. (2005). Very high resolution interpolated climate surfaces for global land areas. International Journal of Climatology, 25, 1965-1978. http://dx.doi.org/10.1002/joc.1276.

Hilbert, C., \& Schmullius, C. (2012). Influence of surface topography on ICESat/GLAS forest height estimation and waveform shape. Remote Sensing, 4, 2210-2235.

Hofton, M. A., Minster, J. B., \& Blair, J. B. (2000). Decomposition of laser altimeter waveforms. IEEE Transactions on Geoscience and Remote Sensing, 38, 1989-1996.

Houghton, R. A. (2005). Aboveground forest biomass and the global carbon balance. Global Change Biology, 11, 945-958.

Huete, A., Didan, K., Miura, T., Rodriguez, E. P., Gao, X., \& Ferreira, L. G. (2002). Overview of the radiometric and biophysical performance of the MODIS vegetation indices. Remote Sensing of Environment, 83, 195-213.

Hyde, P., Dubayah, R., Walker, W., Blair, J. B., Hofton, M., \& Hunsaker, C. (2006). Mapping forest structure for wildlife habitat analysis using multi-sensor (LiDAR, SAR/InSAR, ETM +, quickbird) synergy. Remote Sensing of Environment, $102,63-73$.

Iqbal, I. A. (2010). Evaluating the potential of ICESat/GLAS data to estimate canopy height in the New Forest National Park, UK, Master thesis, 2010. University of Twente.

Jiao, Z. T., Li, X. W., Wang, J. D., \& Zhang, H. (2011). Assessment of MODIS BRDF shape indicators. Journal of Remote Sensing, 15, 432-443.

Keller, M., Oliveira, R., Jr., Camargo, P., Espirito-Santo, F., \& Hunter, M. (2007). LBA-ECO TG07 forest structure measurements for GLAS validation: Santarem 2004. Data Set. Available on-line [http://www.daac.ornl.gov] from Oak Ridge, Tennessee, U.S.A.: Oak Ridge National Laboratory Distributed Active Archive Center

Kimes, D. S., Ranson, K. J., Sun, G., \& Blair, J. B. (2006). Predicting LiDAR measured forest vertical structure from multi-angle spectral data. Remote Sensing of Environment, 100, 503-511.

Lee, S., Ni-Meister, W., \& Yang, W. (2011). Physically based vertical vegetation structure retrieval from ICESat data: Validation using LVIS in White Mountain National Forest, New Hampshire, USA. Remote Sensing of Environment, 115, 2776-2785.

Lefsky, M. A. (2010). A global forest canopy height map from the moderate resolution imaging spectroradiometer and the Geoscience Laser Altimeter System. Geophysical Research Letters, 37, L15401. http://dx.doi.org/10.1029/2010GL043622.

Lefsky, M. A., Harding, D. J., Keller, M., Cohen, W. B., Carabajal, C. C., Del Bom EspiritoSanto, F., ... de Oliveira, R., Jr. (2005). Estimates of forest canopy height and aboveground biomass using ICESat. Geophysical Research Letters, 32, L22S02. http://dx.doi. org/10.1029/2005GL023971.

Lefsky, M. A., Keller, M., Pang, Y., de Camargod, P. B., \& Hunter, M. O. (2007). Revised method for forest canopy height estimation from Geoscience Laser Altimeter System waveforms. Journal of Applied Remote Sensing, 1 (013537-1-013537-18).

Lefsky, M. A., Cohen, W. B., Harding, D. J., Parker, G. G., Acker, S. A., \& Gower, S. T. (2001) Lidar remote sensing of aboveground biomass in three biomes. International Archives of Photogrammetry and Remote Sensing, Volume XXXIV-3/W4 Annapolis, MD, 22-24 Oct. 2001 (pp. 155-160).

Li, A. N., Huang, C. Q., Sun, G. Q., Shi, H., Toney, C., Zhu, Z. L., ... Masek, J. G. (2011). Modeling the height of young forests regenerating from recent disturbances in Mississippi using Landsat and ICESat data. Remote Sensing of Environment, 115, 1837-1849.

Los, S. O., Rosette, J. A. B., Kljun, N., North, P. R. J., Su'arez, J.C., Hopkinson, C., ... Berni, J.A.J. (2011). Vegetation height products between 60_ S and 60_ N from ICESat GLAS data. Geoscientific Model Development Discussion, 4, 2327-2363.

Luyssaert, S., Inglima, I., Jung, M., et al. (2007). The $\mathrm{CO}_{2}$-balance of boreal, temperate and tropical forests derived from a global database. Global Change Biology, 13, 2509-2537.

Luyssaert, S., Inglima, I., \& Jung, M. (2008). Global forest ecosystem structure and function data for carbon balance research. Data set. Available on-line [http://daac.ornl.gov/] from Oak Ridge, Tennessee, U.S.A.: Oak Ridge National Laboratory Distributed Active Archive Center. http://dx.doi.org/10.3334/ORNLDAAC/949.

Mclver, D.K., \& Friedl, M.A. (2002). Using prior probabilities in decision-tree classification of remotely sensed data. Remote Sensing of Environment, 81, 253-261.

Moholdt, G., Nuth, C., Hagen, J.O., \& Kohler, J. (2010). Recent elevation changes of Svalbard glaciers derived from ICESat laser altimetry. Remote Sensing of Environment, 114(11), 2756-2767.

Nakai, T., Sumida, A., Yuji, K., Hara, T., \& Ohta, T. (2010). A comparison between various definitions of forest stand height and aerodynamic canopy height. Agricultural and Forest Meteorology, 150, 1225-1233.

Nelson, R. (2010). Model effects on GLAS-based regional estimates of forest biomass and carbon. International Journal of Remote Sensing, 31(5), 1359-1372.

Nepstad, D.C., \& Moutinho, P.R. (2013). LBA-ECO LC-14 biophysical measurements, rainfall exclusion, Tapajos National Forest. Data set. Available online [http://daac.ornl.gov] from Oak Ridge, Tennessee, USA.: Oak Ridge National Laboratory Distributed Active Archive Center. http://dx.doi.org/10.3334/ORNLDAAC/1196.

Neuenschwander, A.L., Urban, T.J., Gutierrez, R., \& Schutz, B.E. (2008). Characterization of ICESat/GLAS waveforms over terrestrial ecosystems: Implications for vegetation mapping. Journal of Geophysical Research, 113, G02S03. http://dx.doi.org/10.1029/ $2007 J G 000557$.

Nicodemus, K.K., Malley, J.D., Strobl, C., \& Ziegler, A. (2010). The behaviour of random forest permutation based variable importance measures under predictor correlation. BMC Bioinformatics, 11, 110.

Pang, Y., Lefsky, M., Sun, G.Q., Miller, M.E., \& Li, Z.Y. (2008). Temperate forest height estimation performance using ICESAT GLAS data from different observation periods. The International Archives of the Photogrammetry. Remote Sensing and Spatial Information Sciences, Vol. XXXVII. (pp. 777-782) Part B7. Beijing.

Pflugmacher, D. (2007). Remote sensing of forest aboveground biomass using the Geoscience Laser Altimeter System. Master thesis. Oregon State: University.

Rich, P.M., \& Fournier, R. (1999). BOREAS TE-23 map plot data. Data set. Available on-line [http://www.daac.ornl.gov] from Oak Ridge, Tennessee, U.S.A.: Oak Ridge National Laboratory Distributed Active Archive Center. http://dx.doi.org/ 10.3334/ORNLDAAC/359.

Rosette, J.A.B., North, J.P.R., \& Suarez, J.C. (2008). Vegetation height estimates for a mixed temperate forest using satellite laser altimetry. International Journal of Remote Sensing, 29, 1475-1493.

Rosette, J.A.B., North, P.R.J., Sua'rez, J.C., \& Los, S.O. (2010). Uncertainty within satellite LiDAR estimations of vegetation and topography. International Journal of Remote Sensing, 31, 1325-1342.

Saatchi, S.S., Harris, N.L., Brown, S., Lefsky, M., Mitchard, E.T.A., Salas, W., ... Morel, A. (2011). Benchmark map of forest carbon stocks in tropical regions across three continents. Proceedings of the National Academy of Sciences, 108, 9899-9904.

Sandmeier, S., Müller, C., Hosgood, B., \& Andreoli, G. (1998). Physical mechanisms in hyperspectral BRDF data of grass and watercress. Remote Sensing of Environment, $66,222-233$.

Schaaf, C.B., Gao, F., Strahler, A.H., Lucht, W., Li, X., Tsang, T., ... Roy, D. (2002). First operational BRDF/albedo nadir reflectance products from MODIS. Remote Sensing of Environment, 83, 135-148.

Schull, M.A., Ganguly, S., Samanta, A., Huang, D., Shabanov, N.V., \& Jenkins, J.P. (2007) Physical interpretation of the correlation between multi-angle spectral data and canopy height. Geophysical Research Letters, 34, L18405. http://dx.doi.org/10.1029/ 2007 GL031143.

Schutz, B.E., Zwally, H.J., Shuman, C.A., Hancock, D., \& DiMarzio, J.P. (2005). Overview of the ICESat mission. Geophysical Research Letters, 32, L21S01. http://dx.doi.org/10. 1029/2005GL024009.

Selkowitz, D.J., Green, G., Peterson, B., \& Wylie, B. (2012). A multi-sensor LiDAR, multispectral and multi-angular approach for mapping canopy height in boreal forest regions. Remote Sensing of Environment, 121, 458-471.

Sexton, J.O., Song, X.P., Feng, M., Noojipady, P., Anand, A., Huang, C.Q., ... Townshend, J.R. (2013). Global, 30-m resolution continuous fields of tree cover: Landsat-based rescaling of MODIS vegetation continuous fields with LiDAR-based estimates of error. International Journal of Digital Earth, 6(5), 427-448. http://dx.doi.org/10.1080/ 17538947.2013.786146.

Shi, Y.L., Choi, S.H., Ni, X.L., Ganguly, S., Zhang, G., Duong, H.V., ... Myneni, R.B. (2013). Allometric scaling and resource limitations model of tree heights: Part 1. Model optimization and testing over continental USA. Remote Sensing, 5, 284-306. http://dx.doi. org/10.3390/rs5010284.

Shuman, C.A., Zwally, H.J., Schutz, B.E., Brenner, A.C., DiMarzio, J.P., Suchdeo, V.P., \& Fricker, H.A. (2006). ICESat Antarctic elevation data: Preliminary precision and accuracy assessment. Geophysical Research Letters, 33, L07501. http://dx.doi.org/10.1029/ 2005 GL025227.

Simard, M., Pinto, N., Fisher, J.B., \& Baccini, A. (2011). Mapping forest canopy height globally with spaceborne LiDAR. Journal of Geophysical Research, 116, G04021. http://dx. doi.org/10.1029/2011JG001708.

Simard, M., Zhang, K.Q., Rivera-Monroy, V.H., Ross, M.S., Ruiz, P.L., Castañeda-Moya, E., .. Rodriguez, E. (2006). Mapping height and biomass of mangrove forests in Everglades National Park with SRTM elevation data. Photogrammetric Engineering \& Remote Sensing, 72, 299-311.

Song, C., Dickinson, M.B., Su, L., Zhang, S., \& Yausse, Y.D. (2010). Estimating average tree crown size using spatial information from Ikonos and QuickBird images: Acrosssensor and across-site comparisons. Remote Sensing of Environment, 114, 1099-1107.

Strobl, C., \& Zeileis, A. (2008). Danger: High power! - Exploring the statistical properties of a test for random forest variable importance. Proceedings of the 18th International Conference on Computational Statistics, Porto, Portugal, 2008.

Strobl, C., Boulesteix, A., Zeileis, A., \& Hothorn, T. (2007). Bias in random forest variable importance measures: Illustrations, sources and a solution. BMC Bioinformatics, $8,25$.

Sun, G., Ranson, K.J., Kimes, D.S., Blair, J.B., \& Kovacs, K. (2008). Forest vertical structure from GLAS: An evaluation using LVIS and SRTM data. Remote Sensing of Environment, 112, 107-117.

Tian, X., Su, Z.B., Chen, E.X., Li, Z.Y., Tol, C.V.D., Guo, J.P., \& He, Q.S. (2012). Reprint of: Estimation of forest above-ground biomass using multi-parameter remote sensing data over a cold and arid area. International Journal of Applied Earth Observation and Geoinformation, 17, 102-110.

Turner, D.P., Cohen, W.B., Kennedy, R.E., Fassnacht, K.S., \& Briggs, J.M. (1999). Relationships between leaf area index and Landsat TM spectral vegetation indices across three temperate zone sites. Remote Sensing of Environment, 70, 52-68.

Urban, T.J., Schutz, B.E., \& Neuenschwander, A.L. (2008). Survey of ICESat coastal altimetry applications: continental coast, open ocean island, and inland river. Terrestrial, Atmospheric and Oceanic Sciences, 19, 1-19. 
U.S. Geological Survey (2006). Shuttle Radar Topography Mission, 30 Arc Second product, version 2.0. University of Maryland, College Park, Md: Global Land Cover Facility http:// www.glcf.umd.edu/data/srtm/.

Wang, C., Tang, F. X., Li, L. W., Li, G. C., Cheng, F., \& Xi, X. H. (2013). Wavelet analysis for ICESat/GLAS waveform decomposition and its application in average tree height estimation. IEEE Geoscience and Remote Sensing Letters, 10, 115-119.
Wang, Z. S., Schaaf, C. B., Lewis, P., Knyazikhin, Y., Schull, M. A., Strahler, A. H., ... Blair, B. J. (2011). Retrieval of canopy height using moderate-resolution imaging spectroradiometer (MODIS) data. Remote Sensing of Environment, 115, 1595-1601.

Zolkos, S. G., Goetz, S. J., \& Dubayah, R. (2013). A meta-analysis of terrestrial aboveground biomass estimation using LiDAR remote sensing. Remote Sensing of Environment, 128, 289-298. 